\title{
Influence of Donor-Acceptor Distance Variation on Photoinduced Electron and Proton Transfer in Rhenium(I)- Phenol Dyads
}

\begin{tabular}{|r|l|}
\hline Journal: & Journal of the American Chemical Society \\
\hline Manuscript ID: & ja-2012-053046.R1 \\
\hline Manuscript Type: & Article \\
\hline Date Submitted by the Author: & 27-Jun-2012 \\
\hline Complete List of Authors: & $\begin{array}{l}\text { Kuss-Petermann, Martin; University of Goettingen, Institute of Inorganic } \\
\text { Chemistry } \\
\text { Wolf, Hilke; University of Goettingen, Institute of Inorganic Chemistry } \\
\text { Stalke, Dietmar; University of Goettingen, Institute of Inorganic Chemistry } \\
\text { Wenger, Oliver; University of Goettingen, Institute of Inorganic Chemistry }\end{array}$ \\
\hline
\end{tabular}

\section{SCHOLARONE ${ }^{\text {m }}$ \\ Manuscripts}




\title{
Influence of Donor-Acceptor Distance Variation on
}

\author{
Photoinduced Electron and Proton Transfer in
}

Rhenium(I)-Phenol Dyads

\author{
Martin Kuss-Petermann, Hilke Wolf, Dietmar Stalke, Oliver S. Wenger* \\ Georg-August-Universität Göttingen, Institut für Anorganische Chemie, Tammannstrasse 4, D-37077 \\ Göttingen, Germany. \\ oliver.wenger@chemie.uni-goettingen.de
}

RECEIVED DATE (to be automatically inserted after your manuscript is accepted if required according to the journal that you are submitting your paper to)

\section{ABSTRACT}

A homologous series of four molecules in which a phenol unit is linked covalently to a rhenium(I) tricarbonyl diimine photooxidant via a variable number of $p$-xylene spacers $(\mathrm{n}=0-3)$ was synthesized and investigated. The species with a single $p$-xylene spacer was structurally characterized to get some benchmark distances. Photoexcitation of the metal complex in the shortest dyad $(n=0)$ triggers release of the phenolic proton to the acetonitrile/water solvent mixture; an H/D kinetic isotope effect (KIE) of 2.0 \pm 0.4 is associated with this process. Thus, the shortest dyad basically acts like a photoacid. The next longer dyads $(\mathrm{n}=1,2)$ exhibit intramolecular photoinduced phenol-to-rhenium electron transfer in the rate-determining excited-state deactivation step, and there is no significant KIE in this case. For the 
dyad with $\mathrm{n}=1$, transient absorption spectroscopy provides evidence for release of the phenolic proton to the solvent once the phenol has been oxidized by intramolecular photoinduced electron transfer. Subsequent thermal charge-recombination is associated with an H/D KIE of $3.6 \pm 0.4$ and therefore is likely to involve proton motion in the rate-determining reaction step. Thus, some of the longer dyads (n $=1,2)$ exhibit photoinduced proton-coupled electron transfer (PCET), albeit in a stepwise (electron transfer followed by proton transfer) rather than concerted manner. Our study demonstrates that electronically strongly coupled donor-acceptor systems may exhibit significantly different photoinduced PCET chemistry than electronically weakly coupled donor-bridge-acceptor molecules.

\section{INTRODUCTION}

Proton-coupled electron transfer (PCET) is an important elementary step in many biochemical processes, photosynthesis being a particularly relevant example. ${ }^{1-8}$ If we are to emulate natural photosynthesis in artificial systems, thorough understanding of all factors governing PCET rates and efficiencies appears indispensable. Although fundamental aspects of PCET chemistry can be investigated directly on suitable enzymes, the use of chemically simpler artificial molecular models is very popular. ${ }^{9}$ Phenols are attractive in this context because their hydroxylic proton becomes highly acidic upon oxidation, ${ }^{10-11}$ hence these molecules can act as combined electron/proton donors. ${ }^{12,13-14}$ Certain phenol systems can be viewed as models for the $\mathrm{Tyr}_{Z} / \mathrm{His}-190$ PCET interface in photosystem II (Scheme 1a): ${ }^{13,15-29}$ Light absorption by chlorophyll leads to the formation of a highly oxidizing porphyrin molecule $\left(\mathrm{P}_{680}{ }^{-+}\right)$which is reduced by $\mathrm{Tyr}_{\mathrm{Z}}$, and presumably this is coupled to transfer of the phenolic proton to the nearby His-190 base. ${ }^{6,30}$ A central question of many fundamental PCET investigations is whether the overall reaction is a concerted process, or whether there are individual electron and proton transfer steps. Many phenol-containing systems react via concerted proton-electron transfer (CPET) ${ }^{13,15-29}$ but stepwise mechanisms in which initial electron transfer is followed by proton 
transfer (ETPT) have also been reported. ${ }^{31-33}$ Some aspects regarding the PCET chemistry of phenols have received particular attention in recent years, for example the influence of solvent $\mathrm{pH}$ on drivingforces and rates, the importance of buffer ions as proton acceptors, and the special role played by water as a medium in which PCET takes place. ${ }^{34-38,39}$

Scheme 1. (a) PCET between the tyrosine $\mathrm{Z}$, histidine $\mathrm{f}_{190}$, and chlorophyll $\mathrm{P}_{680}$ components of photosystem II; (b) Rhenium(I) tricarbonyl photosensitizers with appended 2,6-di(t-butyl)phenol units investigated in this work $(\mathrm{n}=0,1,2,3)$.

(a)

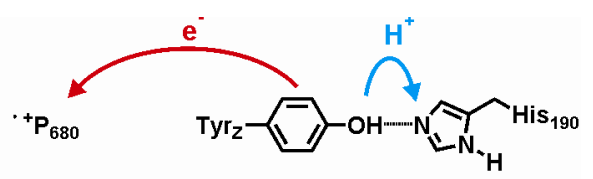

(b)

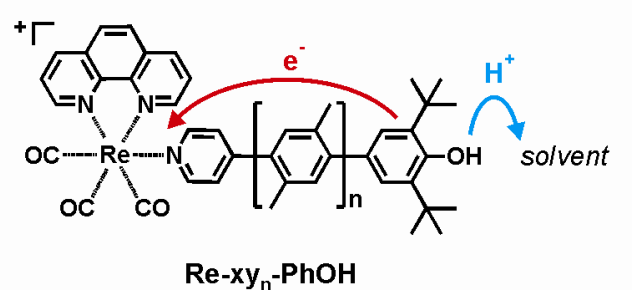

It is not uncommon that in the course of a PCET reaction the participating electron is transferred over a significantly longer distance than the proton. There are systems in which the concerted proton-electron transfer mechanism is dominant even though electron donor and electron acceptor are separated by more than 6 A. However, while the distance dependence of pure electron transfer has long been studied, ${ }^{40-41}$ the distance dependence of PCET is yet poorly explored and has only recently come into the focus of attention. ${ }^{42-43,44-45}$ PCET has in fact four relevant distances, namely the electron and proton transfer distances, and the separations between proton and electron in the donor and in the acceptor. Here, we focus on the influence of distance between the proton- and electron-accepting units in bidirectional (multi-site) PCET with the rigid rod-like molecules shown in Scheme 1b. 2,6-di(t-butyl)phenol (PhOH) is used as a combined electron-proton donor, a rhenium(I) tricarbonyl phenanthroline complex (Re) is employed as a photooxidant, and a solvent molecule in immediate neighborhood to the phenol is acting 
as proton acceptor. The distance between the two redox partners can be varied from 7.9 to $20.8 \AA$ through introduction of one up to three $p$-xylene (xy) units, and this leads to a simultaneous increase of the distance between the electron accepting center and the proton accepting site. These molecules can be viewed as functional models for the $\mathrm{Tyr}_{\mathrm{Z}} / \mathrm{His}-190 / \mathrm{P}_{680}$ reaction triple of photosystem II.

\section{RESULTS AND DISCUSSION}

Synthesis and X-ray crystal structure. Synthesis of the molecules from Scheme $1 \mathrm{~b}$ occurs in a modular fashion as described previously by us for analogous rhenium/ruthenium-(oligo- $p$-xylene)phenothiazine systems. ${ }^{46-50}$ Detailed synthetic protocols and molecule characterization data are given in the Supporting Information. The result of an X-ray crystal structure analysis of Re- $\mathrm{xy}_{1}-\mathrm{PhOH}$ is shown in Figure 1.

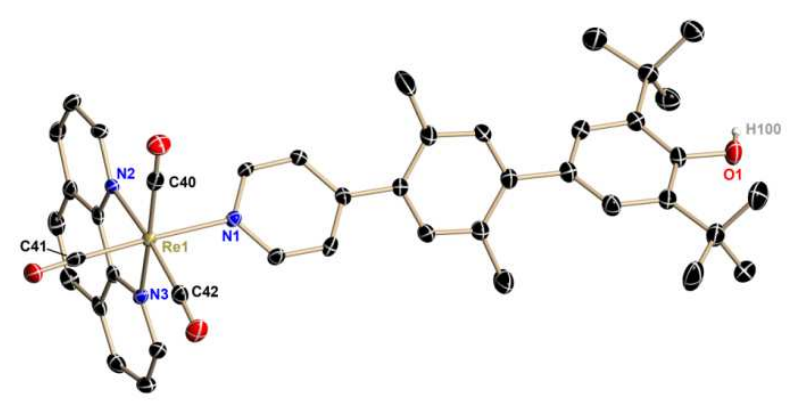

Figure 1. Crystallographic structure of the Re- $x y_{1}-\mathrm{PhOH}$ cation. Displacement ellipsoids are drawn at the $50 \%$ probability level. Hydrogen atoms, anions, and co-crystallized solvent molecules are omitted.

Re- $\mathrm{xy}_{1}-\mathrm{PhOH}$ crystallizes in the monoclinic space group $\mathrm{C} 2 / \mathrm{c}$ with a single molecule in the asymmetric unit containing the $\mathrm{Re}-\mathrm{xy}_{1}-\mathrm{PhOH}$ unit and the triflate counterion. Additionally, a dichloromethane and a disordered diethyl ether solvent molecule are present in the asymmetric unit. As 
shown in Figure 1 the Re atom is coordinated by three carbonyl-, one pyridine-, and one phenanthroline ligand to form an almost perfect octahedral coordination polyhedron. While the equatorial positions are occupied by two carbonyl and the phenanthroline ligands, the perfect square is only slightly distorted with the N3-Re-N2 angle being the smallest at $75.94^{\circ}$ and the N2-Re-C40 angle being the widest at $97.26^{\circ}$ (Table 1). Located at the axial positions first there is a carbonyl group while the other vertex is formed by the pyridine- $\mathrm{xy}_{1}-\mathrm{PhOH}-\mathrm{entity}$. The C41-Re-N1 unit is forming an almost perfectly linear arrangement with an angle of $177.72^{\circ}$. Regarding the Re-N bonds one finds the axial Re-N bond slightly elongated compared to the equatorial (2.205 $\AA$ vs. $2.175 / 2.181 \AA$ respectively). Thus, the bond lengths vary within the expected range. The three Re-CO bonds are almost all of the same lengths, showing no elongation in the axial position.

Table 1. Selected bond lengths and -angles

\begin{tabular}{llll} 
& $\begin{array}{l}\text { bond } \\
\text { lengths }[\AA]\end{array}$ & $\begin{array}{l}\text { bond } \\
\text { angles [] }\end{array}$ \\
\hline Re1-N1 & $2.205(2)$ & N2-Re1-N3 & $75.94(9)$ \\
Re1-N2 & $2.181(3)$ & C42-Re1-C40 & $91.86(14)$ \\
Re1-N3 & $2.175(3)$ & N2-Re1-C40 & $97.26(12)$ \\
Re1-C40 & $1.920(4)$ & N3-Re1-C42 & $94.98(12)$ \\
Re1-C41 & $1.928(3)$ & C41-Re1-N1 & $92.25(11)$ \\
Re1-C42 & $1.912(3)$ & &
\end{tabular}

The most important piece of information which can be extracted from this structure is that the distance between the center of the phenol and the rhenium atom is $12.2 \AA$, corresponding to the centerto-center electron transfer distance in this compound. One further extracts a length of $4.3 \AA$ for a xylene repeating unit, and thus we conclude that the electron donor-acceptor distances $\left(\mathrm{R}_{\mathrm{DA}}\right)$ in $\mathrm{Re}-\mathrm{xy}_{0}-\mathrm{PhOH}$, Re-xy $2-\mathrm{PhOH}$, and $\mathrm{Re}-\mathrm{xy}_{3}-\mathrm{PhOH}$ are $7.9 \AA, 16.5 \AA$, and $20.8 \AA$, respectively. In the structure of Re-xy- 
$\mathrm{PhOH}$ the dihedral angle between the phenol and xylene planes $\left(57^{\circ}\right)$, and the angle between the xylene and pyridine planes $\left(41^{\circ}\right)$ are in the typical range for oligo- $p$-phenylene systems. ${ }^{51-54}$ However, while the magnitude of these torsion angles has an important influence on electronic coupling between donor and acceptor, ${ }^{55-57}$ little can be learned from the solid state structure regarding the situation in solution.
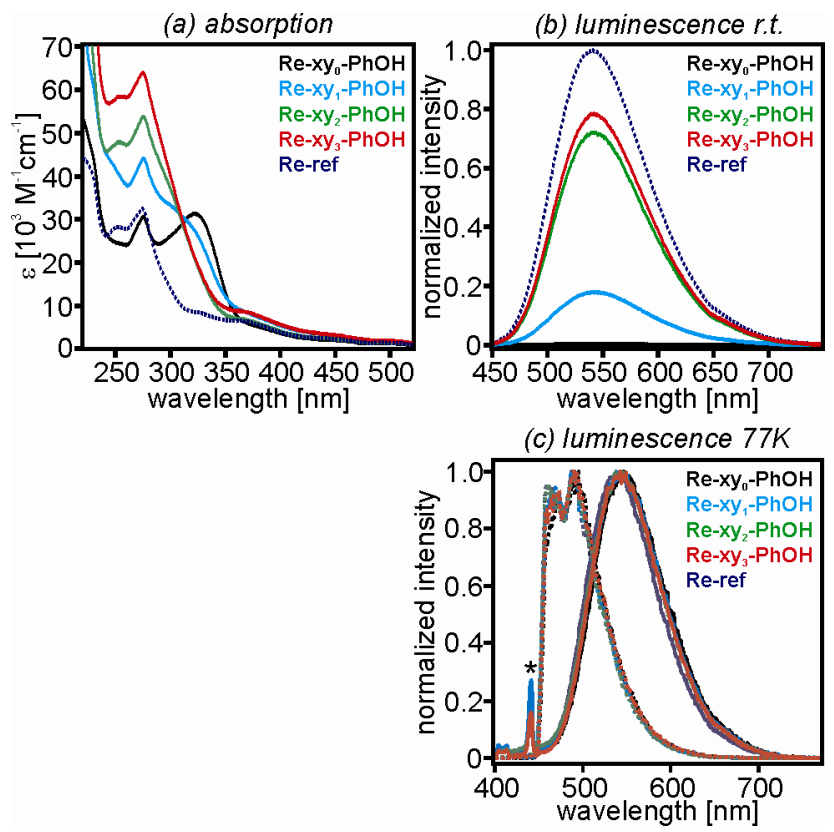

Figure 2. (a) Optical absorption spectra of the four molecules from Scheme $1 \mathrm{~b}$ and a reference complex in acetonitrile solution; (b) Normalized luminescence spectra of the same compounds in 1:1 acetonitrile/water mixture at $25^{\circ} \mathrm{C}$. Excitation occurred at $410 \mathrm{~nm}$. Note that the emission spectrum of Re- $\mathrm{xy}_{0}-\mathrm{PhOH}$ almost coincides with the $\mathrm{x}$-axis. (c) Normalized luminescence spectra of the same compounds in 2-methyltetrahydrofuran at room temperature (solid lines) and at $77 \mathrm{~K}$ (dashed lines). Excitation occurred at $410 \mathrm{~nm}$. The asterisk in (c) denotes Raman scattering peaks.

Optical absorption and emission. Figure 2a shows the UV-vis spectra of the four molecules from Scheme $1 b$ (solid lines) in acetonitrile solution. The purple dashed line is the spectrum of the trifluoromethanesulfonate salt of $\left[\operatorname{Re}(\text { phen })(C O)_{3}(p y)\right]^{+}($phen $=1,10$-phenanthroline; py $=$ pyridine $)$ which was used as a reference complex (hereafter referred to as "Re-ref") incapable of exhibiting any 
PCET, proton transfer or intramolecular electron transfer reactivity. All 5 absorption spectra show a prominent absorption maximum at $275 \mathrm{~nm}$ due to a phenanthroline-localized $\pi-\pi^{*}$ transition. ${ }^{58-59}$ In the spectrum of Re- $\mathrm{xy}_{0}-\mathrm{PhOH}$ there is a band maximum at $323 \mathrm{~nm}$ due to a transition with phenol-topyridine charge transfer character. ${ }^{60}$ The intensity of this band decreases rapidly with increasing donoracceptor distance, being noticeable merely as a shoulder already in the spectrum of Re- $\mathrm{xy}_{1}-\mathrm{PhOH}$. This is an important observation because it demonstrates how rapidly the electronic communication between the phenol and the rhenium complex decreases as a function of distance; on the other hand, this observation is not much of a surprise, given the known exponential distance dependence of superexchange interactions and the fact that a $p$-xylene spacer has a length of $\sim 4.3 \AA .^{41,61-62}$

Bridge lengthening is further observed to lead to increasing extinction at wavelengths shorter than 350 $\mathrm{nm}$, which can be explained by increasing $\pi$-conjugation between mutually connected phenol, $p$-xylene, and pyridine units. As commonly the case for rhenium(I) tricarbonyl diimines, metal-to-ligand charge transfer (MLCT) absorptions occur around $380 \mathrm{~nm}^{58}$

Figure $2 \mathrm{~b}$ shows that the lowest-lying ${ }^{3} \mathrm{MLCT}$ states are emissive in all 5 compounds when dissolved in 1:1 (v:v) acetonitrile/water solution, albeit with significantly different luminescence quantum yields. Following excitation at $410 \mathrm{~nm}$ and correcting for differences in absorbance between individual solutions at this wavelength, the strongest emission is observed for the reference complex while in the Re- $\mathrm{xy}_{\mathrm{n}}-\mathrm{PhOH}$ molecules the luminescence gets weaker with decreasing donor-acceptor distance (decreasing $n$ ). For $n=0$, the emission spectrum almost coincides with the $\mathrm{x}$-axis. We note that in the protic $\mathrm{CH}_{3} \mathrm{CN} / \mathrm{H}_{2} \mathrm{O}$ mixture considered here the luminescence lifetime of $\mathrm{Re}-\mathrm{xy}_{0}-\mathrm{PhOH}$ is much shorter than that of Re-ref (40 ns vs. $1270 \mathrm{~ns}$, see below), hence intensity and lifetime decrease go hand in hand when $\mathrm{CH}_{3} \mathrm{CN}$ is mixed with $\mathrm{H}_{2} \mathrm{O}$. The observation of increasing luminescence quenching with decreasing $n$ signals the presence of a nonradiative excited-state deactivation process which is dependent on the phenol-rhenium distance. Emission quenching by triplet-triplet energy transfer can be ruled out on thermodynamic grounds: The $\left[\operatorname{Re}(\mathrm{phen})(\mathrm{CO})_{3}(\mathrm{py})\right]^{+}$complex has a triplet energy $\left(\mathrm{E}_{\mathrm{T}}\right)$ of 
$\sim 2.75 \mathrm{eV},{ }^{63}$ while (unsubstituted) phenol has $\mathrm{E}_{\mathrm{T}}=3.55 \mathrm{eV},{ }^{64}$ and the $p$-xylene units can be expected to have even higher triplet energies. ${ }^{65}$ Consequently, the emission quenching observed in Figure $2 \mathrm{~b}$ is most likely either due to photoinduced electron transfer, proton transfer, or a combination of both (PCET).

Given the observation of strong rhenium(I)-phenol coupling in $\mathrm{Re}-\mathrm{xy}_{0}-\mathrm{PhOH}$ we performed lowtemperature emission experiments in order to test whether the emissive excited state is indeed the same in all four dyads. Figure $2 \mathrm{c}$ shows the results from experiments in which $10^{-5} \mathrm{M}$ solutions of the dyads in 2-methyl-tetrahydrofuran (MTHF) were excited at $390 \mathrm{~nm}$ at room temperature (solid lines) and at 77 $\mathrm{K}$ as a frozen solution (dashed lines). The four emission spectra were normalized arbitrarily to an intensity of 1.0 at the emission band maximum for better direct comparison. This procedure makes it obvious that the four emission bands are virtually identical, and one may conclude that the emissive excited-state is the same in all four dyads, at least at $77 \mathrm{~K}$. However, the relative energies of excitedstates of rhenium(I) tricarbonyl diimines can change when going from fluid solution to rigid glasses, ${ }^{58}$ hence we cannot know for sure whether at $298 \mathrm{~K}$ the conclusion from above still holds true. On the other hand, there is no evidence for a rigidochromic effect in our systems. The observation of vibrational fine structure in $77 \mathrm{~K}$ emission spectra is common for rhenium(I) tricarbonyl diimines and signals participation of intraligand $\left(\pi-\pi^{*}\right)$ states to the low temperature luminescence. ${ }^{58-59}$

\section{Cyclic voltammetry. The electrochemical potentials of the redox-active phenol and rhenium(I) units in} the four dyads from Scheme $1 \mathrm{~b}$ were determined using cyclic voltammetry. Actual voltammograms are shown in the Supporting Information, here we merely report the redox potentials as determined in dry acetonitrile solution in presence of $0.1 \mathrm{M}$ tetrabutylammonium hexafluorophosphate $\left(\mathrm{TBAPF}_{6}\right)$ electrolyte (Table 2).

The first thing we note is that the phenol oxidations are irreversible, as frequently observed for phenols. ${ }^{10}$ In this situation we estimate their half-wave potentials from the inflection point occurring in the rise of the respective redox wave when sweeping from low to high potentials. There appears to be no 
dependence of the redox potentials determined in this manner from the potential sweep rate, at least not in the range between $10 \mathrm{mV} / \mathrm{s}$ to $300 \mathrm{mV} / \mathrm{s}$.

The shortest member $\left(\mathrm{Re}-\mathrm{xy}_{0}-\mathrm{PhOH}\right)$ stands out from the dyad series in that it exhibits a phenol oxidation potential which is markedly different from those of the three longer congeners $\left(\mathrm{Re}_{-} \mathrm{xy}_{1-3^{-}}\right.$ $\mathrm{PhOH})$. Oxidation of the 2,6-di(t-butyl)phenol unit in Re- $\mathrm{xy}_{0}-\mathrm{PhOH}$ occurs at a potential of $1.2 \mathrm{~V}$ vs. $\mathrm{Fc}^{+} / \mathrm{Fc}$, while in the $\mathrm{Re}-\mathrm{xy}_{1-3}-\mathrm{PhOH}$ dyads potentials of only about $1.0 \mathrm{~V}$ vs. $\mathrm{Fc}^{+} / \mathrm{Fc}$ are necessary (Figure S1). This is yet another manifestation of stronger interaction of the phenol with its neighboring molecular units in Re- $\mathrm{xy}_{0}-\mathrm{PhOH}$ compared to the longer dyads (in addition to the observation of phenolto-pyridine charge transfer absorption bands in $\mathrm{Re}-\mathrm{xy}_{0}-\mathrm{PhOH},{ }^{60}$ see above). We initially presumed that due to the proximity of the cationic rhenium(I) complex the phenol unit in Re- $\mathrm{xy}_{0}-\mathrm{PhOH}$ is oxidized less readily than in the longer congeners where the electrostatic influence from the metal site is expected to be weaker. However, cyclic voltammetry of the free pyridine- $(p \text {-xylene })_{n}-\mathrm{PhOH}$ ligands (see Figure S3 of the Supporting Information) reveals that this is not primarily an electrostatic effect because we observe a similar difference (of about $0.2 \mathrm{~V}$ ) between the phenol oxidation potentials of the free ligands as between $\mathrm{Re}-\mathrm{xy}_{0}-\mathrm{PhOH}$ and $\mathrm{Re}-\mathrm{xy}_{1-3}-\mathrm{PhOH}$. It appears plausible that the true physical origin of this $0.2 \mathrm{~V}$ potential shift is strong electronic interaction between phenol and pyridine when these two units are coupled directly to one another. The reason for this may be the electron-withdrawing character of pyridine.

Table 2. Geometrical parameters, electrochemical potentials (in Volts vs. $\mathrm{Fc}^{+} / \mathrm{Fc}$ ), and driving-forces for photoinduced electron transfer $\left(\Delta \mathrm{G}_{\mathrm{ET}}\right)$ in the four dyads from Scheme $1 \mathrm{~b} . \mathrm{R}_{\mathrm{DA}}$ is the center-to-center electron transfer distance. $E\left(\mathrm{PhOH}^{+} / \mathrm{PhOH}\right)$ is the electrochemical potential for oxidation of the phenol component in the dyads, $E\left(\mathrm{PhO}^{-} / \mathrm{PhO}\right)$ is the potential for oxidation of the deprotonated form of the phenol, and $E\left(\operatorname{Re}^{\mathrm{I}} / \mathrm{Re}^{0}\right)$ is the electrochemical potential for reduction of the rhenium(I) unit in the four dyads. The electrochemical potentials were measured in dry acetonitrile solution containing $0.1 \mathrm{M}$ 
$\mathrm{TBAPF}_{6}$. See Supporting Information for voltammograms.

\begin{tabular}{llllll} 
& $\mathrm{R}_{\mathrm{DA}}$ & $E\left(\mathrm{PhOH}^{+} /\right.$ & $E\left(\mathrm{PhO}^{-} /\right.$ & $E\left(\mathrm{Re}^{\mathrm{I}} / \mathrm{Re}^{0}\right)$ & $\Delta G_{\mathrm{ET}}[\mathrm{eV}]$ \\
& {$[\AA]$} & $\mathrm{PhOH})$ & $\mathrm{PhO})$ & & \\
\hline $\mathrm{Re}-\mathrm{xy}_{0}-\mathrm{PhOH}$ & 7.9 & 1.20 & -0.28 & -1.57 & +0.00 \\
$\mathrm{Re}-\mathrm{xy}_{1}-\mathrm{PhOH}$ & 12.2 & 1.01 & -0.59 & -1.54 & -0.20 \\
$\mathrm{Re}-\mathrm{xy} y_{2}-\mathrm{PhOH}$ & 16.5 & 0.98 & -0.64 & -1.54 & -0.22 \\
$\mathrm{Re}-\mathrm{xy} y_{3}-\mathrm{PhOH}$ & 20.9 & 0.99 & -0.63 & -1.54 & -0.21
\end{tabular}

When deprotonating the phenol units by adding sodium methoxide the resulting phenolate moieties are oxidized at $-0.28 \mathrm{~V}$ vs. $\mathrm{Fc}^{+} / \mathrm{Fc}$ in $\mathrm{Re}-\mathrm{xy}_{0}-\mathrm{PhO}^{-}$and at about $-0.6 \mathrm{~V}$ vs. $\mathrm{Fc}^{+} / \mathrm{Fc}$ in $\mathrm{Re}-\mathrm{xy}_{1-3}-\mathrm{PhO}^{-}$, i. e., there is again a substantial difference between the shortest and the longer members of the series (fourth column of Table 2). An analogous observation is made for the free ligands (see Figure S4 of the Supporting Information). For the shortest deprotonated ligand one may draw two resonance structures (Scheme 2) which may help understand why this molecular unit is oxidized less readily than the $p$ xylene-bridged congeners; negative charge can simply be delocalized towards the metal center. We note that this interpretation is in line with the assignment of the 323-nm absorption band in the UV-vis spectrum of Re-xy $-\mathrm{PhOH}$ (Figure 1a) to a phenol-to-pyridine charge transfer transition (see above). ${ }^{60}$

Scheme 2. Two resonance structures of the phenolate-pyridine ligand in deprotonated $\mathrm{Re}-\mathrm{xy}_{0}-\mathrm{PhOH}$.

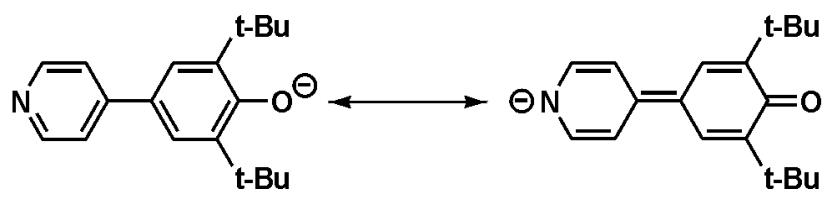

Addition of sodium methoxide to solutions of rhenium(I) tricarbonyl diimine complexes is of some concern because the presence of coordinating $\mathrm{CH}_{3} \mathrm{O}^{-}$may lead to ligand substitution reactions, particularly at the axial position where the pyridine is located. ${ }^{66}$ However, given the observation of clear 
differences between cyclic voltammograms of the shortest member of the series and the longer congeners not only for the dyads (Figure S2) but also for the corresponding free ligands (Figure S4) we conclude that substitution of the pyridine ligand is not occurring to extents that are significant for electrochemical investigations.

In the Re-xy $y_{0-3}-\mathrm{PhOH}$ dyads the rhenium(I) moiety is reduced at potentials between -1.54 and $-1.57 \mathrm{~V}$ vs. $\mathrm{Fc}^{+} / \mathrm{Fc}$ (fifth column of Table 2), and this is in line with literature values for reduction of rhenium(I) tricarbonyl diimines. ${ }^{58}$

On the basis of the phenol oxidation $\left(E_{o x}\right)$ and rhenium $(I)$ reduction potentials $\left(E_{\text {red }}\right)$ from Table 1 one may now use equation 1 to estimate the driving-force for photoinduced electron transfer $\left(\Delta \mathrm{G}_{\mathrm{ET}}\right)$ from the phenol to the ${ }^{3}$ MLCT-excited rhenium complex. ${ }^{67}$

$$
\Delta G_{E T}=e \cdot\left(E_{o x}-E_{r e d}\right)-E_{00}+\frac{e^{2}}{4 \cdot \pi \cdot \varepsilon_{0} \cdot r} \cdot\left(\frac{1}{\varepsilon_{s}}-\frac{1}{\varepsilon_{r e f}}\right)
$$

In equation $1, \mathrm{E}_{00}$ is the energy of the photoactive ${ }^{3} \mathrm{MLCT}$ state of the rhenium complex $(2.75 \mathrm{eV}),{ }^{63}$ $\varepsilon_{0}$ is the vacuum permittivity, $r$ the average radius of the two involved redox partners (assumed to be 4.5 $\AA$ ), $\varepsilon_{\mathrm{s}}$ the dielectric constant of the solvent in which the electrochemical potentials were determined (acetonitrile; 35.94), and $\varepsilon_{\mathrm{r}}$ is the dielectric constant of the solvent used for the spectroscopic measurements $\left(1: 1(\mathrm{v}: \mathrm{v})\right.$ acetonitrile/water; 55.7) ${ }^{68}$ This analysis leads to the conclusion that electron transfer from the phenol units to photoexcited rhenium(I) moieties is expected to be slightly exergonic in the Re-xy ${ }_{1-3}-\mathrm{PhOH}$ dyads (last column of Table 2), but should have essentially no driving-force in $\mathrm{Re}-\mathrm{xy}_{0}-\mathrm{PhOH}$. We note that driving-force estimates based on equation 1 are accurate to $0.1 \mathrm{eV}$ at best, particularly in view of the fact that some of the redox-waves are irreversible (see above).

Phenol deprotonation. The $\mathrm{pK}_{\mathrm{a}}$ value of the phenol in $\mathrm{Re}-\mathrm{xy}_{0}-\mathrm{PhOH}$ in $1: 1$ (v:v) $\mathrm{CH}_{3} \mathrm{CN}_{2} \mathrm{H}_{2} \mathrm{O}$ has 
been determined via UV-vis titration, monitoring the absorption change at $431 \mathrm{~nm}$ upon addition of aqueous sodium hydroxide solution (Figure 3a). The midpoint of the titration (Figure $3 \mathrm{~b}$ ) is found at a $\mathrm{pH}$ meter reading of 11.0 corresponding to an effective $\mathrm{pK}_{\mathrm{a}}$ value of 11.3 in the $1: 1(\mathrm{v}: \mathrm{v})$ acetonitrile/water mixture. ${ }^{69}$ Substantially less prominent spectral changes are observed upon deprotonation of the longer congeners because phenol-pyridine coupling is weaker in $\mathrm{Re}-\mathrm{xy}_{1-3}-\mathrm{PhOH}$ than in $\mathrm{Re}-\mathrm{xy}_{0}-\mathrm{PhOH}$ (titration data not shown). For the Re- $\mathrm{xy}_{2}-\mathrm{PhOH}$ dyad we find a $\mathrm{pK}_{\mathrm{a}}$ value of 11.4 (effective $\mathrm{pK}_{\mathrm{a}}$ in 1:1 (v:v) $\mathrm{CH}_{3} \mathrm{CN} / \mathrm{H}_{2} \mathrm{O}$ ). Acetonitrile/water mixtures had to be used for these experiments because the triflate salts of our complexes are insoluble in pure water and because the acetonitrile/water mixture was also employed for (time-resolved) luminescence and transient absorption spectroscopy (see below).
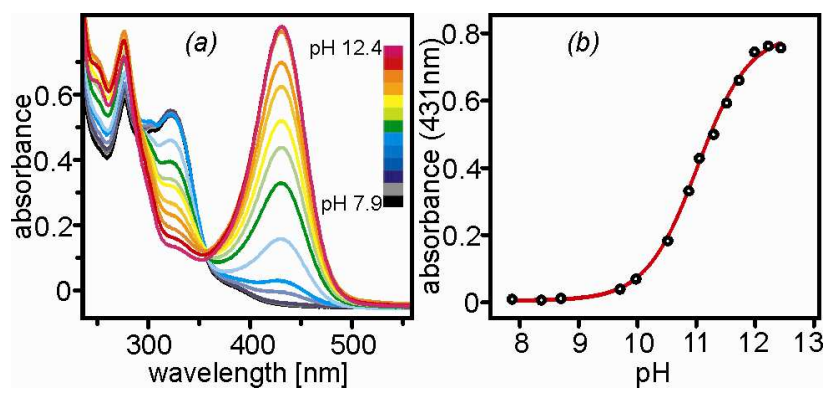

Figure 3. (a) Absorption spectra of $\mathrm{Re}-\mathrm{xy}_{0}-\mathrm{PhOH}$ in 1:1 acetonitrile/water at different $\mathrm{pH}$ values. (b) Titration curve monitoring the absorbance change at $431 \mathrm{~nm}$.

Time-resolved emission. Table 3 reports the luminescence lifetimes of the $\mathrm{Re}-\mathrm{xy}_{\mathrm{n}}-\mathrm{PhOH}$ dyads and the reference complex in four different solvents (or solvent mixtures). In de-oxygenated dichloromethane (second column), the lifetimes of the dyads do not differ significantly from that of the reference complex. In de-oxygenated acetonitrile (third column) the lifetime of $\mathrm{Re}-\mathrm{xy}_{1}-\mathrm{PhOH}$ is markedly shorter than in all other systems, indicating that an additional nonradiative excited-state deactivation mechanism becomes competitive with ${ }^{3}$ MLCT deactivation processes that are inherent to 
the $\left[\operatorname{Re}(\text { phen })(C O)_{3}(p y)\right]^{+}$complex. Triplet-triplet energy transfer has already been ruled out as a possible quenching source (see above), but photoinduced electron transfer is a viable possibility, particularly when considering the $\Delta \mathrm{G}_{\mathrm{ET}}$ values from Table 2: $\Delta \mathrm{G}_{\mathrm{ET}}$ is negative for $\mathrm{Re}-\mathrm{xy}_{1-3}-\mathrm{PhOH}$, but rate constants for electron tunneling (which we expect to be the relevant mechanism for charge transfer in the specific cases of our molecules) drop off exponentially with increasing distance, ${ }^{61-62,70}$ and this may explain the absence of significant quenching for the Re- $\mathrm{xy}_{\mathrm{n}}-\mathrm{PhOH}$ dyads with $\mathrm{n}=2$ and $\mathrm{n}=3$ in $\mathrm{CH}_{3} \mathrm{CN}$. For the system with $\mathrm{n}=0$ there is no driving-force for photoinduced electron transfer $\left(\Delta \mathrm{G}_{\mathrm{ET}}=\right.$ $0 \mathrm{eV}$ ) which may account for the absence of luminescence lifetime quenching in this dyad in pure $\mathrm{CH}_{3} \mathrm{CN}$. The transient absorption data presented below will provide more direct evidence for photoinduced electron transfer in the Re-xy $-\mathrm{PhOH}$ dyad.

Table 3. Luminescence lifetimes and effective H/D kinetic isotope effect ( $\left.\mathrm{KIE}_{\mathrm{eff}}\right)$ of the four dyads from Scheme $1 \mathrm{~b}$ and the $\left[\operatorname{Re}(\mathrm{phen})(\mathrm{CO})_{3}(\mathrm{py})\right]^{+}$reference complex in various solvents under de-oxygenated conditions. Excitation occurred at $410 \mathrm{~nm}$ with 8-ns laser pulses, detection was at $550 \mathrm{~nm}$. See text for definition of $\mathrm{KIE}_{\mathrm{eff}}$.

\begin{tabular}{lccccc} 
& $\mathrm{CH}_{2} \mathrm{Cl}_{2}$ & $\mathrm{CH}_{3} \mathrm{CN}$ & $\mathrm{CH}_{3} \mathrm{CN} / \mathrm{H}_{2} \mathrm{O}$ & $\mathrm{CH}_{3} \mathrm{CN} / \mathrm{D}_{2} \mathrm{O}$ & $\mathrm{KIE}_{\text {eff }}$ \\
& $\tau[\mathrm{ns}]$ & $\tau[\mathrm{ns}]$ & $\tau[\mathrm{ns}]$ & $\tau[\mathrm{ns}]$ & \\
\hline Re-ref & 1220 & 1239 & 1270 & 1588 & \\
Re-xy $-\mathrm{PhOH}$ & 1141 & 986 & 40 & 95 & $2.0 \pm 0.4$ \\
Re-xy $-\mathrm{PhOH}$ & 970 & 582 & 144 & 194 & $1.1 \pm 0.2$ \\
Re-xy $-\mathrm{PhOH}$ & 902 & 1041 & 928 & 1254 & \\
Re-xy $-\mathrm{PhOH}$ & 1136 & 1151 & 1005 & 1378 &
\end{tabular}

In a 1:1 (v:v) mixture of acetonitrile and water (fourth column of Table 3 ) we observe significant lifetime shortening for the $\mathrm{Re}-\mathrm{xy}_{\mathrm{n}}-\mathrm{PhOH}$ dyads with $\mathrm{n}=0-2$, only the longest member of the series appears to exhibit emission which is essentially unquenched with respect to the reference complex. 
Thus, water is an essential ingredient for inducing substantial excited-state quenching in the $R e-\mathrm{xy}_{\mathrm{n}^{-}}$ $\mathrm{PhOH}$ dyads. Interestingly, somewhat longer lifetimes are measured when water is replaced by heavy water (fifth column); Figure 4 shows a direct comparison of luminescence lifetimes $(\tau)$ measured in $\mathrm{CH}_{3} \mathrm{CN} / \mathrm{H}_{2} \mathrm{O}$ (faster decays of a given color) and $\mathrm{CH}_{3} \mathrm{CN} / \mathrm{D}_{2} \mathrm{O}$ (slower decays of a given color). The largest H/D kinetic isotope effect (KIE) is detected for Re-xy $-\mathrm{PhOH}$ for which $\tau_{\mathrm{H}} / \tau_{\mathrm{D}}=2.4$, the smallest for Re-ref for which $\tau_{\mathrm{H}} / \tau_{\mathrm{D}}=1.3$. The observation of a KIE for the reference complex most likely reflects the fact that multiphonon relaxation of the ${ }^{3}$ MLCT excited state is less effective in the deuterated solvent, and this can be expected to occur in all three dyads. Thus we find it useful to define an effective KIE ( $\left.\mathrm{KIE}_{\text {eff }}\right)$ which factors out this solvent effect on multiphonon relaxation and which therefore reflects the true H/D KIE of the photochemistry occurring from ${ }^{3}$ MLCT-excited rhenium(I). The resulting effective KIEs are reported in the last column of Table 3, and we note that only for the Re-

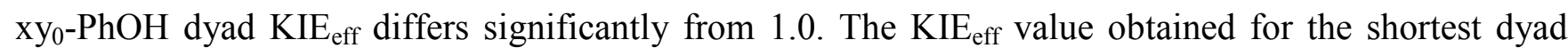
$(2.0 \pm 0.4)$ suggests that the rate-determining excited-state deactivation process involves proton motion, while in the longer dyads there is most likely only electron motion involved. Since luminescence quenching is rather weak in $\mathrm{Re}-\mathrm{xy}_{2}-\mathrm{PhOH}$ and $\mathrm{Re}-\mathrm{xy}_{3}-\mathrm{PhOH}$ we refrain from reporting KIEs for these two dyads (see also comments below).
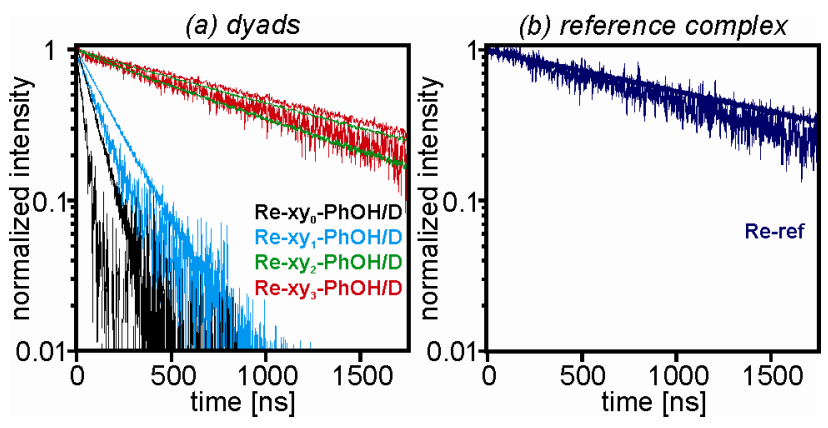

Figure 4. (a) Decays of the luminescence signals of the Re- $\mathrm{xy}_{\mathrm{n}}-\mathrm{PhOH}$ molecules in de-oxgygenated 1:1 $\mathrm{CH}_{3} \mathrm{CN} / \mathrm{H}_{2} \mathrm{O}$ (faster decays of a given color) and $\mathrm{CH}_{3} \mathrm{CN} / \mathrm{D}_{2} \mathrm{O}$ (slower decays of a given color) after pulsed excitation at $410 \mathrm{~nm}$ (pulse width: $\sim 8 \mathrm{~ns}$ ); intensities have been arbitrarily normalized to a value 
of 1 at $\mathrm{t}=0$; (b) Luminescence decay of the reference complex under identical conditions.

Equation 2 is commonly used to estimate rate constants $\left(\mathrm{k}_{\mathrm{Q}}\right)$ for excited-state quenching from luminescence lifetimes.

$$
\mathrm{k}_{\mathrm{Q}}=\tau^{-1}-\tau_{\mathrm{ref}}^{-1}
$$

Here, $\tau$ is the lifetime of the Re- $\mathrm{xy}_{\mathrm{n}}-\mathrm{PhOH}$ luminescence, and $\tau_{\text {ref }}$ is the luminescence lifetime of the reference complex (Re-ref). Rate constants determined in this manner for $\mathrm{CH}_{3} \mathrm{CN} / \mathrm{H}_{2} \mathrm{O}$ and $\mathrm{CH}_{3} \mathrm{CN} / \mathrm{D}_{2} \mathrm{O}$ solutions of the Re- $\mathrm{xy}_{\mathrm{n}}-\mathrm{PhOH}$ molecules are displayed as a function of donor-acceptor distance $\left(\mathrm{R}_{\mathrm{DA}}\right)$ in the semilogarithmic plot of Figure 5. Data measured using $\mathrm{CH}_{3} \mathrm{CN} / \mathrm{H}_{2} \mathrm{O}$ and $\mathrm{CH}_{3} \mathrm{CN} / \mathrm{D}_{2} \mathrm{O}$ is represented in red and green color, respectively. The heights of the vertical lines represent the error bars associated with the individual $\mathrm{k}_{\mathrm{Q}}$-values, and they are based on the experience that each of the luminescence lifetimes can be determined with an experimental accuracy of $\pm 10 \%$. The error bars increase rapidly with increasing $\mathrm{R}_{\mathrm{DA}}$, and they become very large for $\mathrm{Re}-\mathrm{xy}_{2}-\mathrm{PhOH}$ and $\mathrm{Re}-\mathrm{xy}_{3}-\mathrm{PhOH}$ because the luminescence lifetimes of these two dyads approach that of the reference complex (Table 3).

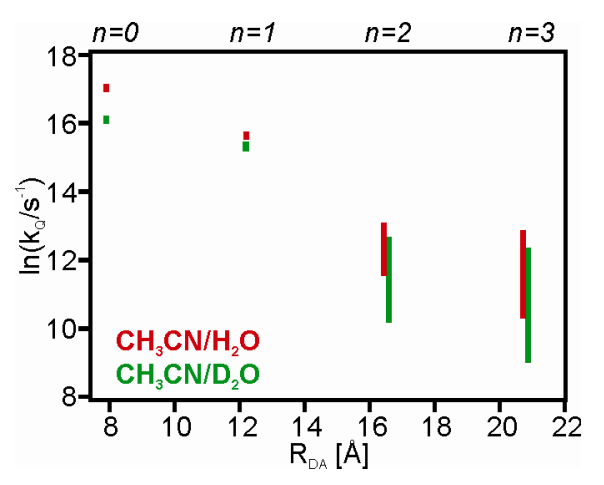

Figure 5. Semilogarthmic representation of the excited-state quenching rate constant $\left(\mathrm{k}_{\mathrm{Q}}\right)$ as a function of phenol-rhenium (center-to-center) distance $\left(\mathrm{R}_{\mathrm{DA}}\right)$ in the four Re- $\mathrm{xy}_{\mathrm{n}}-\mathrm{PhOH}$ molecules in $\mathrm{CH}_{3} \mathrm{CN} / \mathrm{H}_{2} \mathrm{O}$ (red) and $\mathrm{CH}_{3} \mathrm{CN} / \mathrm{D}_{2} \mathrm{O}$ (green). 
Despite the large error bars it is possible to discern a nearly exponential distance dependence of $\mathrm{k}_{\mathrm{Q}}$ as would be expected for intramolecular electron or hole tunneling across the $p$-xylene spacers. Given the observation of $\mathrm{KIE}_{\text {eff }}$ values that differ significantly between $\mathrm{Re}-\mathrm{xy}_{0}-\mathrm{PhOH}$ and its longer congeners, and considering the changeover in excited-state quenching mechanism which is most likely associated with this difference in $\mathrm{KIE}_{\text {eff }}$ (see above) it appears reasonable to extract a distance decay constant (socalled $\beta$-value) for $\mathrm{k}_{\mathrm{Q}}$ from the data for $\mathrm{Re}-\mathrm{xy}_{\mathrm{n}}-\mathrm{PhOH}$ with $\mathrm{n}=1-3$ and to exclude the dyad with $\mathrm{n}=0$ from this analysis; the transient absorption data shown below strongly support this procedure. From a linear regression fit to the $\mathrm{CH}_{3} \mathrm{CN} / \mathrm{H}_{2} \mathrm{O}$ data in Figure 5 we thus find $\beta=0.45 \pm 0.18 \AA^{-1}$, while the $\mathrm{CH}_{3} \mathrm{CN} / \mathrm{D}_{2} \mathrm{O}$ data yields $\beta=0.39 \pm 0.18 \AA^{-1}$. These distance decay constants are in line with those found for analogous oligo- $p$-xylene and oligo- $p$-phenylene systems, ${ }^{55,71}$ but it is to be noted that $\beta$ is not a bridge-specific parameter but rather a function of the entire donor-bridge-acceptor construct. ${ }^{61-62,72}$

\section{Transient absorption spectroscopy. Figure 6a shows transient absorption data obtained after excitation} of the two shortest dyads and the reference complex in de-oxygenated $1: 1(\mathrm{v}: \mathrm{v}) \mathrm{CH}_{3} \mathrm{CN} / \mathrm{H}_{2} \mathrm{O}$ solutions at $355 \mathrm{~nm}$ with laser pulses of $\sim 8 \mathrm{~ns}$ width. The spectra were recorded by time-averaging over the first 200 ns after the laser pulse. The reference complex exhibits a transient absorption spectrum which is typical for ${ }^{3}$ MLCT excited rhenium(I) tricarbonyl diimines (purple trace): There is a bleach of the $\pi-\pi^{*}$ absorption of neutral phen at $275 \mathrm{~nm}$ while a positive transient absorption signal, characteristic for the reduced phen ligand, ${ }^{73}$ is observed at $300 \mathrm{~nm}$. The signals decay with lifetimes of $1217 \mathrm{~ns}$ (at $275 \mathrm{~nm}$ ) and $1324 \mathrm{~ns}$ (at $300 \mathrm{~nm}$ ) respectively, both in line with the luminescence lifetime measured for this compound under identical conditions (fourth column of Table 3).

The transient absorption spectrum of the $\mathrm{Re}-\mathrm{xy}_{1}-\mathrm{PhOH}$ dyad (blue trace) looks qualitatively similar to that of the reference complex, suggesting at first glance that one primarily observes the spectral signature of the ${ }^{3} \mathrm{MLCT}$ excited-state in this case. A subtle but important difference to the spectrum of 
Re-ref (purple trace) is the occurrence of a relatively weak bleach at $325 \mathrm{~nm}$, i. e., at the wavelength at which the ground-state absorption spectrum of $\mathrm{Re}-\mathrm{xy}_{1}-\mathrm{PhOH}$ exhibits a shoulder that we attributed above to an electronic transition with phenol-to-pyridine charge transfer character (Figure 2a). This particular bleach is diagnostic for the one-electron reduced rhenium complex, and this fact will be important below when discussing the reaction kinetics of the Re- $\mathrm{xy}_{1}-\mathrm{PhOH}$ dyad. Here, we now focus primarily on the transient absorption spectrum measured for the Re- $\mathrm{xy}_{0}-\mathrm{PhOH}$ molecule (black trace in Figure 6a).

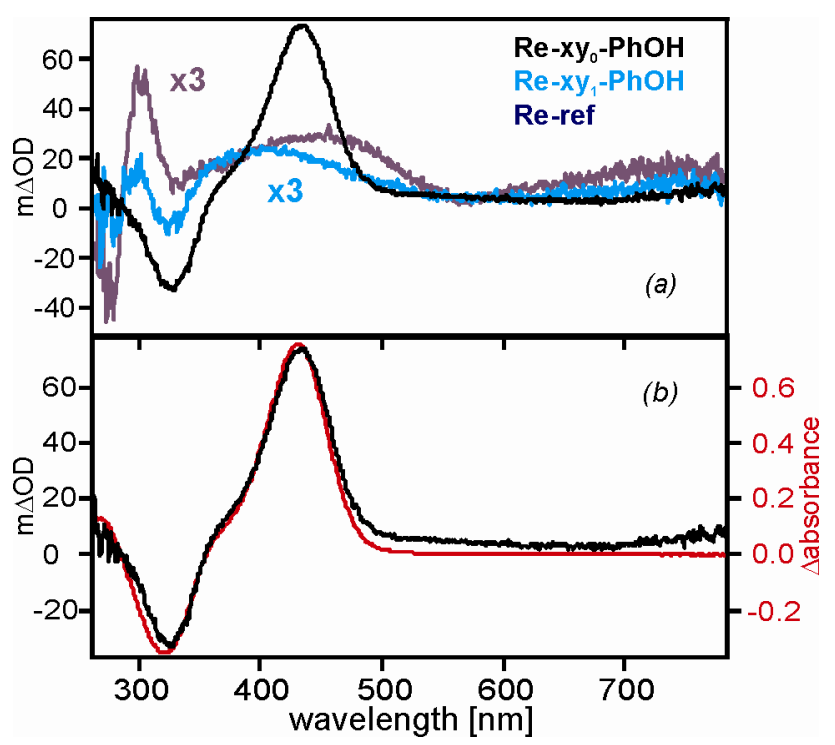

Figure 6. (a)Transient absorption spectra of $\mathrm{Re}-\mathrm{xy}_{\mathrm{n}}-\mathrm{PhOH}(\mathrm{n}=0,1)$ and Re-ref in de-oxygenated 1:1 (v:v) acetonitrile/water. Excitation occurred at $355 \mathrm{~nm}$ with laser pulses of $\sim 8 \mathrm{~ns}$ width. Detection was in a time window of $200 \mathrm{~ns}$ after the laser pulse. (b) Superposition of the experimental transient absorption spectrum of $\mathrm{Re}-\mathrm{xy}_{0}-\mathrm{PhOH}$ (black trace) and a derived spectrum (red trace) obtained from subtraction of the absorption spectrum of $\mathrm{Re}-\mathrm{xy}_{0}-\mathrm{PhOH}$ at $\mathrm{pH} 7.9$ (black trace in Figure 3a) from the absorption spectrum of Re- $\mathrm{xy}_{0}-\mathrm{PhOH}$ at $\mathrm{pH} 12.4$ (red trace in Figure 3a).

The transient absorption spectrum of the shortest dyad (black trace in Figure 6a and 6b) differs very significantly from those of the $\mathrm{Re}-\mathrm{xy}_{1}-\mathrm{PhOH}$ dyad and the reference complex. Using comparable 
excitation pulse energies and dyad concentrations the observed $\Delta \mathrm{OD}$ values are not only substantially higher (suggesting longer lived photoproducts), but there are also significant spectral differences: The bleach at $275 \mathrm{~nm}$ and the positive signal at $300 \mathrm{~nm}$ (usually indicative of phen ${ }^{-}$) are absent, but there is now a new bleach at $330 \mathrm{~nm}$ and a new absorption peaking at $435 \mathrm{~nm}$. The red trace in Figure $6 \mathrm{~b}$ is the result of a subtraction of the $\mathrm{Re}-\mathrm{xy}_{0}-\mathrm{PhOH}$ absorption spectrum at $\mathrm{pH}=7.9$ (black trace in Figure 3a) from the respective absorption spectrum at $\mathrm{pH}=12.4$ (red trace in Figure $3 \mathrm{a}$ ). The superposition of this derived spectrum and the experimental transient absorption spectrum in Figure $6 \mathrm{~b}$ demonstrates quite convincingly that photoexcitation of $\mathrm{Re}-\mathrm{xy}_{0}-\mathrm{PhOH}$ induces phenol deprotonation. In other words, the Re- $\mathrm{xy}_{0}-\mathrm{PhOH}$ dyad acts as a photoacid. This finding is in line with the absence of luminescence lifetime quenching in this dyad in $\mathrm{CH}_{2} \mathrm{Cl}_{2}$ and pure $\mathrm{CH}_{3} \mathrm{CN}$ (second and third column of Table 3) where there are no protonatable reaction partners available. By contrast, in acetonitrile/water mixtures protonation of $\mathrm{OH}^{-}$or $\mathrm{H}_{2} \mathrm{O}$ species may occur, and excited-state quenching is comparatively rapid (fourth and fifth column of Table 3). Furthermore, this finding is in line with the occurrence of a significant kinetic isotope effect $\left(\mathrm{KIE}_{\mathrm{eff}}=2.0 \pm 0.4\right.$, last column Table 3) for excited-state quenching in $\mathrm{Re}-\mathrm{xy}_{0}-\mathrm{PhOH}$. Excited-state deactivation by proton transfer also makes sense in view of the fact that there is essentially no driving-force for photoinduced electron transfer in this particular dyad (last column of Table 2).

Charge transfer kinetics in $R e-x y_{1}-P h O H$. In a prior section we interpreted excited-state quenching in the three longer dyads $\left(\mathrm{Re}-\mathrm{xy}_{1-3}-\mathrm{PhOH}\right)$ in terms of photoinduced electron transfer because there is significant exothermicity associated with this process (contrary to $\mathrm{Re}-\mathrm{xy}_{0}-\mathrm{PhOH}$ ) and because there is no significant H/D kinetic isotope effect in the luminescence quenching data (Table 3); moreover triplettriplet energy transfer quenching is thermodynamically unlikely. Unfortunately, the transient absorption spectrum of Re-xy $-\mathrm{PhOH}$ in Figure 6a (light blue trace) fails to provide completely unambiguous evidence for oxidation products. Phenol radical cations and phenoxyl radicals have well defined absorptions in the $350-500 \mathrm{~nm}$ spectral range, ${ }^{74-75}$ but we are unable to unambiguously detect any of 
these species by transient absorption spectroscopy because in the same spectral range there appear to be absorptions from the reduced rhenium moiety. The spectral signature of the reduced rhenium complex in turn is somewhat difficult to distinguish from the spectrum of ${ }^{3}$ MLCT-excited rhenium because the dominant features are a bleach at $275 \mathrm{~nm}$ and a positive signal at $300 \mathrm{~nm}$ due to transient reduction of the phen ligand, ${ }^{73,88}$ but this is the case not only for the one-electron reduced form of the complex but also for its ${ }^{3}$ MLCT-excited form. As mentioned above, the most diagnostic feature of the one-electron reduced rhenium complex in $\mathrm{Re}-\mathrm{xy}_{1}-\mathrm{PhOH}$ is the weak bleach observed at $325 \mathrm{~nm}$ (blue trace in Figure 6a). This bleach cannot be observed for ${ }^{3} \mathrm{MLCT}$-excited $\left[\operatorname{Re}(\text { phen })(\mathrm{CO})_{3}(\mathrm{py})\right]^{+}$.

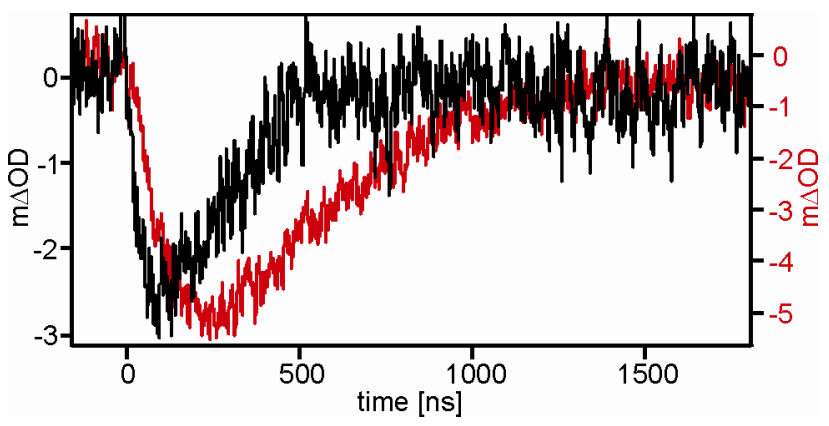

Figure 7. Temporal evolution of the transient absorption signal of Re- $\mathrm{xy}_{1}-\mathrm{PhOH}$ at $325 \mathrm{~nm}$ in deoxygenated 1:1 (v:v) $\mathrm{CH}_{3} \mathrm{CN} / \mathrm{H}_{2} \mathrm{O}$ (black trace) and 1:1 (v:v) $\mathrm{CH}_{3} \mathrm{CN} / \mathrm{D}_{2} \mathrm{O}$ (red trace) after pulsed excitation at $355 \mathrm{~nm}$. Pulse width was $\sim 8 \mathrm{~ns}$.

Figure 7 shows the temporal evolution of the diagnostic bleach at $325 \mathrm{~nm}$ of Re-xy $-\mathrm{PhOH}$ in 1:1 (v:v) $\mathrm{CH}_{3} \mathrm{CN} / \mathrm{H}_{2} \mathrm{O}$ (black trace) and 1:1 (v:v) $\mathrm{CH}_{3} \mathrm{CN} / \mathrm{D}_{2} \mathrm{O}$ (red trace) after excitation at $355 \mathrm{~nm}$ with laser pulses of $\sim 8 \mathrm{~ns}$ duration. The two transients are noticeably different, both in the formation part of the bleach as well as regarding the bleach recoveries at times longer than $100-250 \mathrm{~ns}$. 
Scheme 3. Reaction sequence models for Re- $\mathrm{xy}_{1}-\mathrm{PhOH}$.

(a)

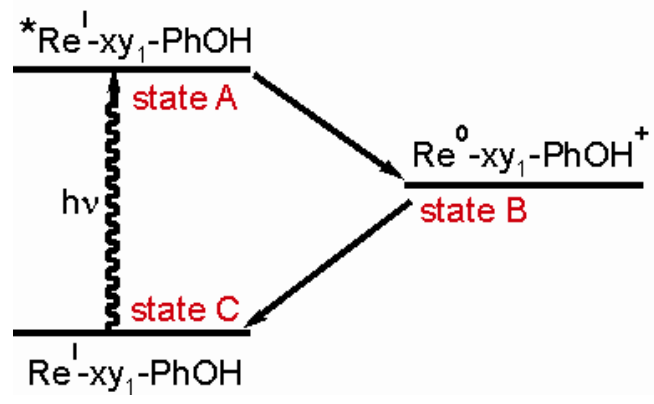

(b)

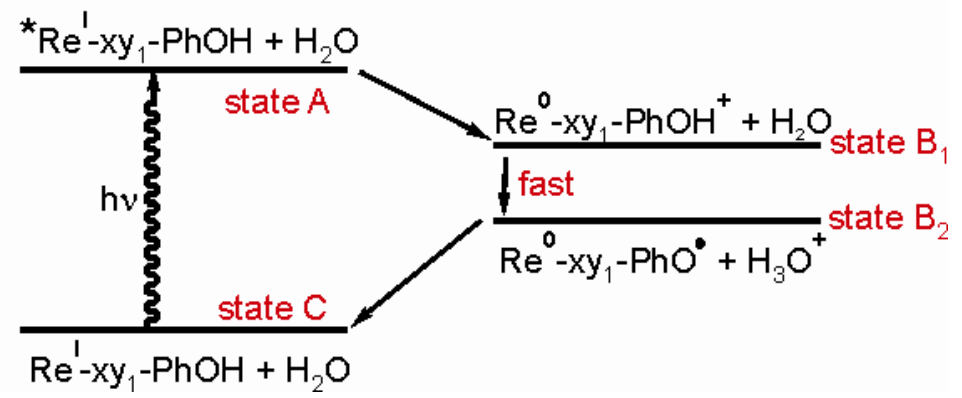

We analyzed the two transients in Figure 7 using a kinetic model for an $\mathrm{A} \rightarrow \mathrm{B} \rightarrow \mathrm{C}$ reaction sequence. In this model, $\mathrm{A}$ is the initial photoexcited state, $\mathrm{B}$ is the charge-separated state with reduced rhenium, and $\mathrm{C}$ is the final (ground) state (Scheme 3a). Based on a fit to the black transient in Figure 7 we obtain time constants of $148 \mathrm{~ns}$ and $85 \mathrm{~ns}$ (Table 4). It appears tempting and most straightforward to associate the faster component ( $85 \mathrm{~ns}$ ) to the build-up of state B (A $\rightarrow$ B step) while the slower time constant (148 ns) would be attributed to the disappearance of state $\mathrm{B}(\mathrm{B} \rightarrow \mathrm{C}$ step). However, in $\mathrm{A} \rightarrow \mathrm{B}$ $\rightarrow \mathrm{C}$ reaction sequences the risetime for the population of state $\mathrm{B}$ need not necessarily correspond to the kinetics of the reaction step $\mathrm{A} \rightarrow \mathrm{B}$, but it may instead reflect the kinetics for step $\mathrm{B} \rightarrow \mathrm{C} .{ }^{54,76-77}$ There is evidence for exactly this scenario in the $\mathrm{Re}-\mathrm{xy}_{1}-\mathrm{PhOH}$ dyad (in $\mathrm{CH}_{3} \mathrm{CN} / \mathrm{H}_{2} \mathrm{O}$ solution) because the slower time constant (148 ns) in fact closely approaches the ${ }^{3}$ MLCT lifetime extracted from luminescence measurements (144 ns, Table 3). In the luminescence experiments we monitor the disappearance of state $\mathrm{A}$ ( step $\mathrm{A} \rightarrow \mathrm{B}$ ), and hence it appears plausible to conclude that the 148-ns component in the transient absorption data is in fact due to the step $\mathrm{A} \rightarrow \mathrm{B}$. In this picture the 85-ns time constant is then due to the step $\mathrm{B} \rightarrow \mathrm{C}$. 
Table 4. Transient absorption lifetimes and H/D kinetic isotope effects (KIE) for excited-state quenching and charge recombination in $\mathrm{Re}-\mathrm{xy}_{0}-\mathrm{PhOH}$ and $\mathrm{Re}-\mathrm{xy}_{1}-\mathrm{PhOH}$ in de-oxygenated 1:1 (v:v) acetonitrile/water. Excitation occurred at $355 \mathrm{~nm}$ with 8 -ns laser pulses. $\tau_{\mathrm{H}}=$ lifetime in $\mathrm{CH}_{3} \mathrm{CN} / \mathrm{H}_{2} \mathrm{O}$, $\tau_{\mathrm{D}}=$ lifetime in $\mathrm{CH}_{3} \mathrm{CN} / \mathrm{D}_{2} \mathrm{O}$.

\begin{tabular}{|c|c|c|c|c|c|c|}
\hline & \multicolumn{3}{|c|}{ excited-state quenching } & \multicolumn{3}{|c|}{ thermal charge recombination } \\
\hline & $\tau_{\mathrm{H}}[\mathrm{ns}]$ & $\tau_{\mathrm{D}}[\mathrm{ns}]$ & $\mathrm{KIE}_{\text {eff }}$ & $\tau_{\mathrm{H}}[\mathrm{ns}]$ & $\tau_{\mathrm{D}}[\mathrm{ns}]$ & KIE \\
\hline $\mathrm{Re}-\mathrm{xy}_{0}-\mathrm{PhOH}$ & $43^{\mathrm{a}} / 41^{\mathrm{b}} /$ & $95^{\mathrm{a}} / 86^{\mathrm{b}} /$ & $1.8 \pm 0.3^{\mathrm{a}, \mathrm{b}, \mathrm{c}}$ & $13200^{\mathrm{b}} /$ & $47200^{\mathrm{b}} /$ & $3.6 \pm 0.5^{\mathrm{b}} / 3.5 \pm 0.5^{\mathrm{c}}$ \\
\hline & $36^{c}$ & $76^{\mathrm{c}}$ & & $14000^{\mathrm{c}}$ & $49200^{c}$ & \\
\hline $\mathrm{Re}-\mathrm{xy}_{1}-\mathrm{PhOH}$ & $148^{\mathrm{b}}$ & $169^{\mathrm{b}}$ & $1.0 \pm 0.3^{b}$ & $85^{\mathrm{b}}$ & $313^{b}$ & $3.7 \pm 0.5^{\mathrm{b}}$ \\
\hline
\end{tabular}

When analyzing the red transient in Figure 7 in the same manner (i. e., the data obtained for the same dyad in $\mathrm{CH}_{3} \mathrm{CN} / \mathrm{D}_{2} \mathrm{O}$ ), we obtain time constants of $169 \mathrm{~ns}$ and 313 ns (Table 4). The ${ }^{3}$ MLCT lifetime extracted from luminescence measurements in this case was 194 ns (Table 3), hence it appears plausible to assign the 169-ns time constant observed in transient absorption spectroscopy to the step $\mathrm{A} \rightarrow \mathrm{B}$, while the 313-ns time constant then logically is due to the reaction step B $\rightarrow$ C. In view of the fact that we have two complementary sets of data (time-resolved luminescence and transient absorption) these assignments appear plausible. $^{78}$

In the framework of our kinetic model the $B \rightarrow C$ reaction step is associated with a sizeable $H / D$ kinetic isotope effect ( $3.7 \pm 0.5$; ratio between $313 \mathrm{~ns}$ and $85 \mathrm{~ns})$ which cannot be reconciled with simple electron transfer. Indeed, this H/D KIE strongly suggests that there is proton movement in the $\mathrm{B} \rightarrow \mathrm{C}$ reaction step. This appears peculiar at first glance, but we think there is a very plausible explanation for this observation (Scheme 3b): Once intramolecular phenol-to-rhenium(I) electron transfer has occurred, the oxidized phenol radical cation is a highly acidic species; in the case of tyrosine the $\mathrm{pK}_{\mathrm{a}}$ of the 
phenolic proton drops from a value of $\sim 9$ in the charge-neutral form to a value around -2 in the oxidized species. ${ }^{17,33,79}$ Therefore it appears plausible to assume that when water is present $\left(\mathrm{pK}_{\mathrm{a}}\right.$ of $\left.\mathrm{H}_{3} \mathrm{O}^{+}=-1.7\right)$, the oxidized phenol releases a proton and a neutral phenoxyl radical is formed. This hypothesis is illustrated by Scheme 3b, which gives a more accurate description of the photoinduced chemistry in Re$\mathrm{xy}_{1}-\mathrm{PhOH}$ than Scheme 3a: After the rate-determining initial electron transfer step forming "state $\mathrm{B}_{1}$ " (with oxidized but still protonated phenol), there is rapid proton release to $\mathrm{H}_{2} \mathrm{O}$, thereby forming "state $\mathrm{B}_{2}$ " (with reduced rhenium, neutral phenoxyl radical, and protonated water), but in time-resolved luminescence and transient absorption we only monitor the step $\mathrm{A} \rightarrow \mathrm{B}_{1}$. Re-establishment of the original rhenium(I) dyad (state C) via intramolecular electron transfer must then be coupled to reprotonation of the phenol moiety, and this may explain the occurrence of a significant KIE in step $\mathrm{B}_{2} \rightarrow$ C (also observable in transient absorption spectroscopy). ${ }^{80}$

Charge transfer kinetics in Re- $x_{0_{0}}-\mathrm{PhOH}$. We now turn our attention back to the transient absorption data obtained from the $\mathrm{Re}-\mathrm{xy}_{0}-\mathrm{PhOH}$ dyad. Based on the data in Figure $6 \mathrm{~b}$ we concluded above that this molecule is acting essentially as a photoacid, but we had not yet presented and discussed the reaction kinetics of this dyad.

Figure 8a shows the temporal evolution of the phenol-based transient absorption signals of Re-xy ${ }^{-}$ $\mathrm{PhOH}$ at $435 \mathrm{~nm}$ (upper half) and at $330 \mathrm{~nm}$ (lower half). The black traces were measured in deoxygenated 1:1 (v:v) $\mathrm{CH}_{3} \mathrm{CN} / \mathrm{H}_{2} \mathrm{O}$, the red traces in de-oxygenated $1: 1(\mathrm{v}: \mathrm{v}) \mathrm{CH}_{3} \mathrm{CN} / \mathrm{D}_{2} \mathrm{O}$. It is obvious from this data that there is a significant H/D KIE. The specific risetimes of these signals are on the order of $40 \mathrm{~ns}$ for protonated samples (second column of Table 4) and on the order of $80 \mathrm{~ns}$ for deuterated samples (third column of Table 4), yielding $\mathrm{KIE}=1.8 \pm 0.3$. This transient absorption data is fully consistent with the findings from time-resolved luminescence spectroscopy (Table 3).

In Figure 8c the temporal evolution of the transient absorption signal of $\mathrm{Re}-\mathrm{xy}_{0}-\mathrm{PhOH}$ at $275 \mathrm{~nm}$ (bleach of neutral phen) is shown. The black traces were measured in 1:1 (v:v) $\mathrm{CH}_{3} \mathrm{CN} / \mathrm{H}_{2} \mathrm{O}$, the red 
traces in $1: 1(\mathrm{v}: \mathrm{v}) \mathrm{CH}_{3} \mathrm{CN} / \mathrm{D}_{2} \mathrm{O}$. The time constants for the recovery of these bleaches are 43 ns for the protonated and $95 \mathrm{~ns}$ for the deuterated species, respectively (Table 4), i. e., with a similar H/D KIE as found above from time-resolved luminescence experiments (Table 3). This finding is consistent with photoexcited $\mathrm{Re}-\mathrm{xy}_{0}-\mathrm{PhOH}$ releasing its phenolic proton to the bulk solvent, coupled to simultaneous relaxation to the electronic ground state.

Figure $8 \mathrm{~b}$ shows the decays of the transient absorption signals of Re- $\mathrm{xy}_{0}-\mathrm{PhOH}$ at $435 \mathrm{~nm}$ (upper half) and at $330 \mathrm{~nm}$ (lower half). The decays are remarkably slow and occur with time constants of $14.0 \mu \mathrm{s}$ and $13.2 \mu \mathrm{s}$, respectively, in $\mathrm{CH}_{3} \mathrm{CN} / \mathrm{H}_{2} \mathrm{O}$, and with time constants of $49.2 \mu \mathrm{s}$ and $47.2 \mu \mathrm{s}$, respectively, in $\mathrm{CH}_{3} \mathrm{CN} / \mathrm{D}_{2} \mathrm{O}$. Thus, like in the case of the longer $\mathrm{Re}-\mathrm{xy}_{1}-\mathrm{PhOH}$ dyad, the rate-determining step leading the photoproducts back to the initially present species is associated with a significant H/D KIE. In the specific case of the Re-xy0-PhOH dyad we find $\mathrm{KIE}=3.5 \pm 0.5(435 \mathrm{~nm})$ and $3.6 \pm 0.5(330 \mathrm{~nm})$, while for Re-xy $-\mathrm{PhOH}$ we found $\mathrm{KIE}=3.7 \pm 0.5$ (last column of Table 4).
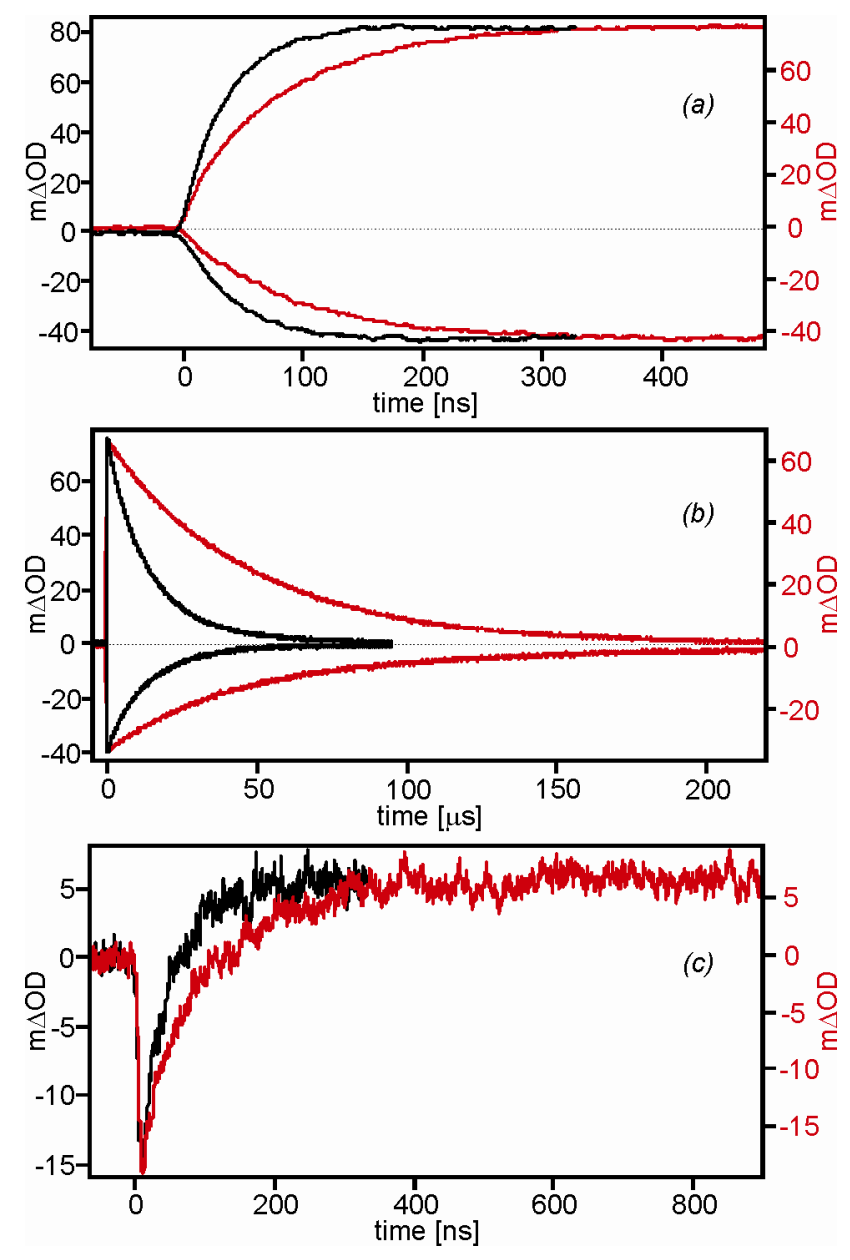
Figure 8. Temporal evolution of the transient absorption signals of $\mathrm{Re}-\mathrm{xy}_{0}-\mathrm{PhOH}$ in de-oxygenated 1:1 (v:v) $\mathrm{CH}_{3} \mathrm{CN} / \mathrm{H}_{2} \mathrm{O}$ (black traces) and $1: 1$ (v:v) $\mathrm{CH}_{3} \mathrm{CN} / \mathrm{D}_{2} \mathrm{O}$ (red traces) at various detection wavelengths: (a, b) at $435 \mathrm{~nm}$ (upper traces) and at $330 \mathrm{~nm}$ (lower traces); note the different time-scale in (a) and (b); (c) at a detection wavelength of $275 \mathrm{~nm}$. Excitation occurred with 8-ns laser pulses at 355 $\mathrm{nm}$ in all cases.

The observation of photoproducts with microsecond lifetimes after photoexcitation of Re-xyo- $\mathrm{PhOH}$ is interesting, particularly in view of the fact that the Re-xy $-\mathrm{PhOH}$ photoproducts exhibit lifetimes on the order of only $\sim 100 \mathrm{~ns}$ (Table 3). We think this discrepancy mainly stems from the fact that the photoproducts are different in these two dyads: The shorter molecule reacts to a $\mathrm{Re}(\mathrm{I})-\mathrm{xy}_{0}-\mathrm{PhO}^{-}$species with a phenolate anion (at least formally, see comments below), the longer congener to a $\operatorname{Re}(0)-\mathrm{xy}_{1^{-}}$ $\mathrm{PhO}$ species with a phenoxyl radical (state $\mathrm{B}_{2}$ in Scheme $3 b$ ). The driving-forces and reorganization energies for re-establishing the initial $\mathrm{Re}(\mathrm{I})-\mathrm{xy}_{0}-\mathrm{PhOH}$ and $\mathrm{Re}(\mathrm{I})-\mathrm{xy}_{1}-\mathrm{PhOH}$ species would be expected to be significantly different, and this can easily manifest in substantially different reaction kinetics. In addition we note that for the $\mathrm{Re}(\mathrm{I})-\mathrm{xy}_{0}-\mathrm{PhO}^{-}$species the resonance structure on the right-hand side of Scheme 2 is presumably more important. Furthermore, it appears plausible to state that this resonance structure is less easily re-protonated at the oxygen atom than the phenolate structure on the left-hand side of Scheme 2.

Transient absorption experiments with the longer $\mathrm{Re}-\mathrm{xy}_{2}-\mathrm{PhOH}$ and $\mathrm{Re}-\mathrm{xy}_{3}-\mathrm{PhOH}$ dyads are largely inconclusive because the photoinduced chemistry in these systems is too slow with respect to the inherent ${ }^{3}$ MLCT lifetime of the rhenium(I) photosensitizer, hence time-resolved absorption studies have been limited to the two shortest dyads.

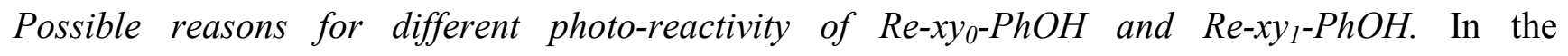
electrochemistry section we noted that the phenol oxidations and some of the rhenium (or more 
precisely the phenanthroline-based) reductions in our dyads are irreversible in cyclic voltammetry. Thus, there is significant uncertainty in the redox potential values reported in Table 2, but nevertheless it seems clear that the Re- $\mathrm{xy}_{0}-\mathrm{PhOH}$ molecule stands out from the dyad series in that it has a phenol oxidation potential which is about $0.2 \mathrm{~V}$ more positive than in the longer dyads. Using equation 1 , this has lead us to the conclusion that photoinduced electron transfer from the phenol units to photoexcited rhenium(I) complexes is expected to be slightly exergonic in the $\mathrm{Re}-\mathrm{xy}_{1-3}-\mathrm{PhOH}$ dyads (last column of Table 2; $\Delta \mathrm{G}_{\mathrm{ET}} \approx-0.2 \mathrm{eV}$ ), but we expect essentially no driving-force in Re- $\mathrm{xy}_{0}-\mathrm{PhOH}$. We think this is one of the key reasons for the different photo-reactivity of the Re- $\mathrm{xy}_{0}-\mathrm{PhOH}$ and $\mathrm{Re}-\mathrm{xy}_{1}-\mathrm{PhOH}$ dyads. Another important reason may be the possible resonance stabilization of the phenolate anion in $\mathrm{Re}^{-\mathrm{xy}_{0}-}$ $\mathrm{PhOH}$; the fact that the phenolate-pyridine unit may adopt a stable quinonoid structure (right half of Scheme 2) ${ }^{81}$ may potentially provide significant driving-force for phototriggered proton release. Scheme 4 illustrates the situation in $\mathrm{Re}-\mathrm{xy}_{0}-\mathrm{PhOH}$. Initial photoexcitation populates mainly the emissive ${ }^{3} \mathrm{MLCT}$ state, which is energetically below the phenol $\rightarrow$ pyridine charge transfer $(\mathrm{CT})$ state. Upon deprotonation (possibly involving the phenol-pyridine CT state itself), the phenol $\rightarrow$ pyridine CT state is energetically stabilized because it is now a phenolate $\rightarrow$ pyridine $\mathrm{CT}$, and this leads to emission quenching and provides the driving-force for the transfer of electron density from the phenolate unit towards the metal center.

Scheme 4. Energy-level scheme showing the most relevant excited-states of Re-xy $\mathrm{y}_{0} \mathrm{PhOH}$ before (a) and after (b) deprotonation.

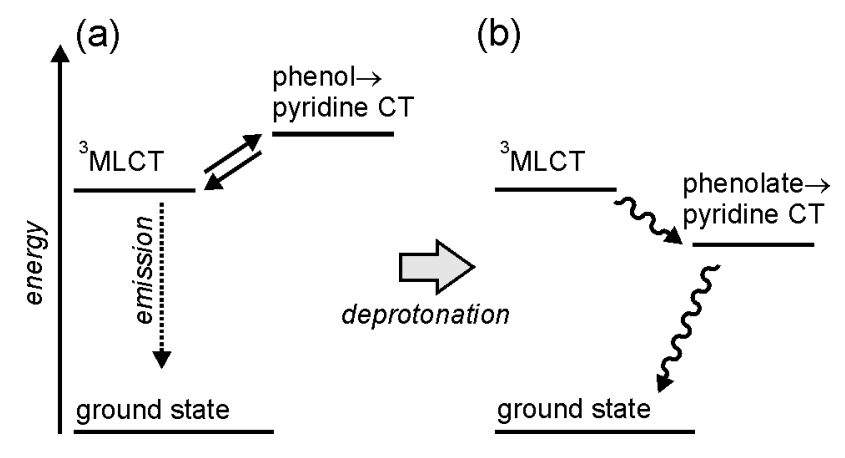


In the $\mathrm{Re}-\mathrm{xy}_{1}-\mathrm{PhOH}$ dyad we expect the phenomenon of different resonance structures to play a much less important role because the phenol and pyridine units are electronically de-coupled from each other by an intervening $p$-xylene spacer.

\section{SUMMARY AND CONCLUSIONS}

The initial aim of this work was to explore how variation of the distance between electron accepting and electron/proton donating sites affects the rates and mechanism of bidirectional (multi-site) PCET in rhenium-(oligo-p-xylene)-phenol molecules. We anticipated that all four dyads from Scheme 1 would exhibit photoinduced PCET chemistry in acetonitrile/water mixtures and wondered how the PCET rates and mechanisms would change with increasing phenol-rhenium distance. Interestingly, we found that the Re- $x y_{0}-\mathrm{PhOH}$ dyad is acting as a photoacid, while the Re- $x y_{1}-\mathrm{PhOH}$ molecule exhibits photoinduced PCET chemistry involving a stepwise electron transfer, proton transfer reaction sequence. However, to some extent, the term "photoacid" does not sufficiently accurately describe the photoinduced chemistry of the Re- $\mathrm{xy}_{0}-\mathrm{PhOH}$ dyad because the deprotonated phenol-pyridine ligand has two resonance structures (Scheme 2). When considering the quinonoid structure on the right of Scheme 2 one may note that electron transfer from the phenolate to the pyridine moiety has taken place; with

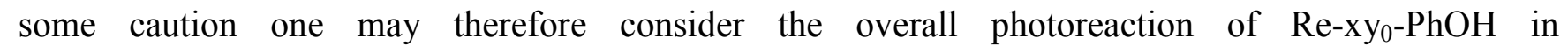
acetonitrile/water as a variant of PCET. At any rate, from our transient absorption studies it is clear that the rate-determining steps in the photoinduced reactions of the donor-acceptor molecule $\mathrm{Re}-\mathrm{xy}_{0}-\mathrm{PhOH}$ and the donor-bridge-acceptor compound $\mathrm{Re}-\mathrm{xy}_{1}-\mathrm{PhOH}$ are different: Proton motion is involved in the case of the shortest dyad $(\mathrm{KIE}=1.8 \pm 0.3)$, while in $\mathrm{Re}-\mathrm{xy}_{1}-\mathrm{PhOH}$ there is no significant $\mathrm{KIE}$ for the photoinduced forward reaction (determined from combined time-resolved emission and transient 
absorption studies). By contrast, the thermal backward reaction of Re- $\mathrm{xy}_{1}-\mathrm{PhOH}$ (like that of Re- $\mathrm{xy}_{0}$ $\mathrm{PhOH}$ ) exhibits $\mathrm{H} / \mathrm{D} \mathrm{KIE}>3$, indicating that proton motion is important in the rate-determining step leading back to the initially present species. Thus our study provides significant new insight into photoinduced PCET chemistry, particularly with respect to the influence of donor-acceptor distance on the overall reaction and the importance of strong electronic coupling between the donor and acceptor units.

\section{EXPERIMENTAL SECTION}

Synthesis, electrochemistry, and optical spectroscopy. Detailed synthetic protocols and characterization data for the four dyads from Scheme $1 \mathrm{~b}$ are given in the Supporting Information. Thinlayer chromatography was performed using Polygram SIL G/UV254 plates from Machery-Nagel, and for column chromatography Silica Gel 60 from the same company was employed. Reaction products were characterized by ${ }^{1} \mathrm{H}$ spectroscopy on a Bruker Avance DRX 300 spectrometer, by ESI mass spectrometry using a Bruker APEX IV (FTICR-MS) instrument, and by elemental analysis (conducted by Susanne Petrich at the Institute for Inorganic Chemistry, Göttingen). Optical absorption spectroscopy was performed using Cary 50 and Cary 300 spectrophotometers from Varian, and steady-state luminescence spectra were measured on a Fluorolog-3 instrument (FL322) from Horiba Jobin-Yvon. For time-resolved luminescence and transient absorption spectroscopy, an LP920-KS instrument from Edinburgh Instruments, equipped with an LP920-K photomultiplier and an iCCD camera from Andor, was used. The excitation source was a Quantel Brilliant b laser equipped with an OPO from Opotek. A Versatat3-200 potentiostat from Princeton Applied Research was used for cyclic voltammetry. A glassycarbon electrode served as the working electrode, and two silver wires were used as a counter-electrode and quasi-reference electrode. Ferrocene was used as an internal reference. Prior to voltage scans at 
rates of $100 \mathrm{mV} / \mathrm{s}$, nitrogen gas was bubbled through the dried solvent. The supporting electrolyte was a 0.1 M solution of tetrabutylammonium hexafluorophosphate.

Crystal structure determination. The single crystal was mounted in inert oil under cryogenic conditions employing the X-Temp2 device. ${ }^{82-84}$ The X-ray data set was collected at $100(2) \mathrm{K}$ on an INCOATEC microfocus source ${ }^{85}$ with mirror-monochromated Mo-Ka radiation $(\lambda=0.71073 \AA)$ and equipped with a Bruker Smart Apex II detector and integrated with SAINT and an empirical absorption correction with SADABS was applied. ${ }^{86}$ The structure was solved with direct methods (SHELXS in SHELXTL Version 2008/3) and refined by full-matrix least-squares methods against F2 (SHELXS in SHELXTL Version 2008/3). ${ }^{87}$ All non-hydrogen-atoms were refined with anisotropic displacement parameters. The hydrogen atoms were refined isotropically on calculated positions using a riding model with their Uiso values constrained to equal to 1.5 times the Ueq of their pivot atoms for terminal $\mathrm{sp}^{3}$ carbon atoms and 1.2 times for all other carbon atoms. An exception is the O1 bonded H100 which position was taken from the residual density map and refined freely.

In $\mathrm{Re}-\mathrm{xy}_{1}-\mathrm{PhOH}$ the diethyl ether solvent molecule was disordered at two positions. The molecule is set on a special position, thus revealing a total of four positions. Disordered moieties were refined using bond lengths and displacement parameter restraints. Crystallographic data (excluding structure factors) for the structures reported in this paper have been deposited with the Cambridge Crystallographic Data Centre as supplementary publication no 838939. Copies of the data can be obtained free of charge on application to CCDC, 12 Union Road, Cambridge CB2 1EZ, UK [fax: (internat.) + 44(1223)336-033; email:deposit@ccdc.cam.ac.uk].

\section{ACKNOWLEDGMENT}

This work was supported by the Deutsche Forschungsgemeinschaft (DFG) through IRTG 1422. We kindly acknowledge funding from the DNRF funded Centre of Materials Crystallography and the 
doctoral programme Catalysis for Sustainable Synthesis, provided by the Land Niedersachsen.

Supporting Information Available. Detailed synthetic protocols and characterization data, additional electrochemical and crystallographic data. This material is available free of charge via the Internet at http://pubs.acs.org.

\section{REFERENCES}

(1) Mayer, J. M., Annu. Rev. Phys. Chem. 2004, 55, 363-390.

(2) Huynh, M. H. V.; Meyer, T. J., Chem. Rev. 2007, 107, 5004-5064.

(3) Reece, S. Y.; Nocera, D. G., Annu. Rev. Biochem. 2009, 78, 673-699.

(4) Magnuson, A.; Anderlund, M.; Johansson, O.; Lindblad, P.; Lomoth, R.; Polivka, T.; Ott, S.; Stensjö, K.; Styring, S.; Sundström, V.; Hammarström, L., Acc. Chem. Res. 2009, 42, 1899-1909.

(5) Hammes-Schiffer, S., Acc. Chem. Res. 2009, 42, 1881-1889.

(6) Dempsey, J. L.; Winkler, J. R.; Gray, H. B., Chem. Rev. 2010, 110, 7024-7039.

(7) Costentin, C.; Robert, M.; Savéant, J.-M., Acc. Chem. Res. 2010, 43, 1019-1029.

(8) Gagliardi, C. J.; Westlake, B. C.; Kent, C. A.; Paul, J. J.; Papanikolas, J. M.; Meyer, T. J., Coord. Chem. Rev. 2010, 254, 2459-2471.

(9) Cukier, R. I.; Nocera, D. G., Annu. Rev. Phys. Chem. 1998, 49, 337-369.

(10) Bordwell, F. G.; Cheng, J. P., J. Am. Chem. Soc. 1991, 113, 1736-1743.

(11) Warren, J. J.; Tronic, T. A.; Mayer, J. M., Chem. Rev. 2010, 110, 6961-7001. 
(12) Biczok, L.; Gupta, N.; Linschitz, H., J. Am. Chem. Soc. 1997, 119, 12601-12609.

(13) Concepcion, J. J.; Brennaman, M. K.; Deyton, J. R.; Lebedeva, N. V.; Forbes, M. D. E.; Papanikolas, J. M.; Meyer, T. J., J. Am. Chem. Soc. 2007, 129, 6968-6969.

(14) Bronner, C.; Wenger, O. S., J. Phys. Chem. Lett. 2012, 3, 70-74.

(15) Mayer, J. M.; Rhile, I. J.; Larsen, F. B.; Mader, E. A.; Markle, T. F.; DiPasquale, A. G., Photosynth. Res. 2006, 87, 3-20.

(16) Lachaud, T.; Quaranta, A.; Pellegrin, Y.; Dorlet, P.; Charlot, M. F.; Un, S.; Leibl, W.; Aukauloo, A., Angew. Chem. Int. Ed. 2005, 44, 1536-1540.

(17) Magnuson, A.; Berglund, H.; Korall, P.; Hammarström, L.; Åkermark, B.; Styring, S.; Sun, L. C., J. Am. Chem. Soc. 1997, 119, 10720-10725.

(18) Sun, L. C.; Burkitt, M.; Tamm, M.; Raymond, M. K.; Abrahamsson, M.; LeGourriérec, D.; Frapart, Y.; Magnuson, A.; Kenéz, P. H.; Brandt, P.; Tran, A.; Hammarström, L.; Styring, S.; Åkermark, B., J. Am. Chem. Soc. 1999, 121, 6834-6842.

(19) Johansson, O.; Wolpher, H.; Borgström, M.; Hammarström, L.; Bergquist, J.; Sun, L. C.; Åkermark, B., Chem. Commun. 2004, 194-195.

(20) Maki, T.; Araki, Y.; Ishida, Y.; Onomura, O.; Matsumura, Y., J. Am. Chem. Soc. 2001, 123, $3371-3372$.

(21) Benisvy, L.; Bittl, R.; Bothe, E.; Garner, C. D.; McMaster, J.; Ross, S.; Teutloff, C.; Neese, F., Angew. Chem. Int. Ed. 2005, 44, 5314-5317.

(22) Rhile, I. J.; Markle, T. F.; Nagao, H.; DiPasquale, A. G.; Lam, O. P.; Lockwood, M. A.; Rotter, K.; Mayer, J. M., J. Am. Chem. Soc. 2006, 128, 6075-6088. 
(23) Quaranta, A.; Lachaud, F.; Herrero, C.; Guillot, R.; Charlot, M. F.; Leibl, W.; Aukauloo, A., Chem. Eur. J. 2007, 13, 8201-8211.

(24) Markle, T. F.; Rhile, I. J.; DiPasquale, A. G.; Mayer, J. M., Proc. Natl. Acad. Sci. U. S. A. 2008, $105,8185-8190$.

(25) Markle, T. F.; Mayer, J. M., Angew. Chem., Int. Ed. 2008, 47, 738-740.

(26) Moore, G. F.; Hambourger, M.; Gervaldo, M.; Poluektov, O. G.; Rajh, T.; Gust, D.; Moore, T. A.; Moore, A. L., J. Am. Chem. Soc. 2008, 130, 10466-10467.

(27) Rhile, I. J.; Mayer, J. M., J. Am. Chem. Soc. 2004, 126, 12718-12719.

(28) Costentin, C.; Robert, M.; Savéant, J. M., J. Am. Chem. Soc. 2006, 128, 4552-4553.

(29) Reece, S. Y.; Nocera, D. G., J. Am. Chem. Soc. 2005, 127, 9448-9458.

(30) Bertini, I.; Gray, H. B.; Stiefel, E. I.; Valentine, J. S., Biological Inorganic Chemistry. University Science Books: Sausalito, California, 2007.

(31) Sjödin, M.; Irebo, T.; Utas, J. E.; Lind, J.; Merenyi, G.; Åkermark, B.; Hammarström, L., J. Am. Chem. Soc. 2006, 128, 13076-13083.

(32) Sjödin, M.; Ghanem, R.; Polivka, T.; Pan, J.; Styring, S.; Sun, L. C.; Sundström, V.; Hammarström, L., Phys. Chem. Chem. Phys. 2004, 6, 4851-4858.

(33) Sjödin, M.; Styring, S.; Wolpher, H.; Xu, Y. H.; Sun, L. C.; Hammarström, L., J. Am. Chem. Soc. 2005, 127, 3855-3863.

(34) Irebo, T.; Johansson, O.; Hammarström, L., J. Am. Chem. Soc. 2008, 130, 9194-9195.

(35) Irebo, T.; Reece, S. Y.; Sjödin, M.; Nocera, D. G.; Hammarström, L., J. Am. Chem. Soc. 2007, 
$129,15462-15464$.

(36) Bonin, J.; Costentin, C.; Louault, C.; Robert, M.; Savéant, J. M., J. Am. Chem. Soc. 2011, 133, $6668-6674$.

(37) Bonin, J.; Costentin, C.; Louault, C.; Robert, M.; Routier, M.; Savéant, J. M., Proc. Natl. Acad. Sci. U. S. A. 2010, 107, 3367-3372.

(38) Costentin, C.; Robert, M.; Savéant, J. M., J. Am. Chem. Soc. 2007, 129, 5870-5879.

(39) Hankache, J.; Hanss, D.; Wenger, O. S., J. Phys. Chem. A 2012, 116, 3347-3358.

(40) Oevering, H.; Paddon-Row, M. N.; Heppener, M.; Oliver, A. M.; Cotsaris, E.; Verhoeven, J. W.; Hush, N. S., J. Am. Chem. Soc. 1987, 109, 3258-3269.

(41) Gray, H. B.; Winkler, J. R., Proc. Natl. Acad. Sci. U. S. A. 2005, 102, 3534-3539.

(42) Manner, V. W.; DiPasquale, A. G.; Mayer, J. M., J. Am. Chem. Soc. 2008, 130, 7210-7211.

(43) Manner, V. W.; Mayer, J. M., J. Am. Chem. Soc. 2009, 131, 9874-9875.

(44) Markle, T. F.; Rhile, I. J.; Mayer, J. M., J. Am. Chem. Soc. 2011, 133, 17341-17352.

(45) Zhang, M.-T.; Irebo, T.; Johansson, O.; Hammarström, L., J. Am. Chem. Soc. 2011, 133, 1322413227.

(46) Hanss, D.; Freys, J. C.; Bernardinelli, G.; Wenger, O. S., Eur. J. Inorg. Chem. 2009, 4850-4859.

(47) Hanss, D.; Walther, M. E.; Wenger, O. S., Chem. Commun. 2010, 46, 7034-7036.

(48) Hanss, D.; Wenger, O. S., Inorg. Chem. 2008, 47, 9081-9084.

(49) Hanss, D.; Wenger, O. S., Inorg. Chem. 2009, 48, 671-680. 
(50) Walther, M. E.; Wenger, O. S., ChemPhysChem 2009, 10, 1203-1206.

(51) Bouzakraoui, S.; Bouzzine, S. M.; Bouachrine, M.; Hamidi, M., J. Mol. Struct. 2005, 725, 3944.

(52) Lukeš, V.; Aquino, A. J. A.; Lischka, H.; Kauffmann, H. F., J. Phys. Chem. B 2007, 111, 79547962.

(53) Grave, C.; Risko, C.; Shaporenko, A.; Wang, Y. L.; Nuckolls, C.; Ratner, M. A.; Rampi, M. A.; Zharnikov, M., Adv. Funct. Mater. 2007, 17, 3816-3828.

(54) Hanss, D.; Wenger, O. S., Eur. J. Inorg. Chem. 2009, 3778-3790.

(55) Weiss, E. A.; Ahrens, M. J.; Sinks, L. E.; Gusev, A. V.; Ratner, M. A.; Wasielewski, M. R., J. Am. Chem. Soc. 2004, 126, 5577-5584.

(56) Weiss, E. A.; Tauber, M. J.; Kelley, R. F.; Ahrens, M. J.; Ratner, M. A.; Wasielewski, M. R., J. Am. Chem. Soc. 2005, 127, 11842-11850.

(57) Hanss, D.; Walther, M. E.; Wenger, O. S., Coord. Chem. Rev. 2010, 254, 2584-2592.

(58) Sacksteder, L.; Zipp, A. P.; Brown, E. A.; Streich, J.; Demas, J. N.; DeGraff, B. A., Inorg. Chem. 1990, 29, 4335-4340.

(59) Wallace, L.; Rillema, D. P., Inorg. Chem. 1993, 32, 3836-3843.

(60) Cargill Thompson, A. M. W.; Smailes, M. C. C.; Jeffery, J. C.; Ward, M. D., J. Chem. Soc., Dalton Trans. 1997, 737-743.

(61) Wenger, O. S., Acc. Chem. Res. 2011, 25-35.

(62) Albinsson, B.; Eng, M. P.; Pettersson, K.; Winters, M. U., Phys. Chem. Chem. Phys. 2007, 9, 
5847-5864.

(63) Connick, W. B.; Di Bilio, A. J.; Hill, M. G.; Winkler, J. R.; Gray, H. B., Inorg. Chim. Acta 1995, $240,169-173$.

(64) Das, P. K.; Encinas, M. V.; Scaiano, J. C., J. Am. Chem. Soc. 1981, 103, 4154-4162.

(65) Lafolet, F.; Welter, S.; Popovic, Z.; De Cola, L., J. Mat. Chem. 2005, 15, 2820-2828.

(66) Hevia, E.; Perez, J.; Riera, L.; Riera, V.; del Rio, I.; Garcia-Granda, S.; Miguel, D., Chem.-Eur. J. 2002, 8, 4510-4521.

(67) Weller, A., Z. Phys. Chem. 1982, 133, 93-98.

(68) Gagliardi, L. G.; Castells, C. B.; Rafols, C.; Roses, M.; Bosch, E., J. Chem. Eng. Data 2007, 52, 1103-1107.

(69) Gagliardi, L. G.; Castells, C. B.; Rafols, C.; Roses, M.; Bosch, E., Anal. Chem. 2007, 79, 31803187.

(70) McConnell, H. M., J. Chem. Phys. 1961, 35, 508-515.

(71) Wenger, O. S., Chem. Soc. Rev. 2011, 40, 3538-3550.

(72) Eng, M. P.; Albinsson, B., Angew. Chem. Int. Ed. 2006, 45, 5626-5629.

(73) Chen, P. Y.; Westmoreland, T. D.; Danielson, E.; Schanze, K. S.; Anthon, D.; Neveux, P. E.; Meyer, T. J., Inorg. Chem. 1987, 26, 1116-1126.

(74) Das, P. K.; Encinas, M. V.; Steenken, S.; Scaiano, J. C., J. Am. Chem. Soc. 1981, 103, 41624166.

(75) Gadosy, T. A.; Shukla, D.; Johnston, L. J., J. Phys. Chem. A 1999, 103, 8834-8839. 
(76) Atkins, P. W., Physical Chemistry. Oxford University Press: 2006.

(77) Borgström, M.; Johansson, O.; Lomoth, R.; Baudin, H. B.; Wallin, S.; Sun, L. C.; Åkermark, B.; Hammarström, L., Inorg. Chem. 2003, 42, 5173-5184.

(78) Transient IR spectroscopy might be able to provide additional insight but this experimental method is not readily available.

(79) Sjödin, M.; Styring, S.; Åkermark, B.; Sun, L. C.; Hammarström, L., J. Am. Chem. Soc. 2000, $122,3932-3936$.

(80) Our transient absorption experiments monitors the re-appearance of state C.

(81) Alternatively the relevant structure might be called a pyridone-like structure.

(82) Kottke, T.; Stalke, D., J. Appl. Crystallogr. 1993, 26, 615-619.

(83) Kottke, T.; Lagow, R. J.; Stalke, D., J. Appl. Crystallogr. 1996, 29, 465-468.

(84) Stalke, D., Chem. Soc. Rev. 1998, 27, 171-178.

(85) Schulz, T.; Meindl, K.; Leusser, D.; Stern, D.; Graf, J.; Michaelsen, C.; Ruf, M.; Sheldrick, G. M.; Stalke, D., J. Appl. Crystallogr. 2009, 42, 885-891.

(86) Sheldrick, G. M. SADABS 2008/2, Göttingen, 2008.

(87) Sheldrick, G. M., Acta Crystallogr., Sect. A. 2008, 64, 112-122.

(88) Záliš, S.; Cosani, C.; Cannizzo, A.; Chergui, M.; Hartl, F.; Vlček, A., Jr. Inorg. Chim. Acta 2011, $374,578-585$. 
The photochemistry of rhenium(I)-phenol dyads was explored by means of transient absorption and time-resolved luminescence spectroscopy. Depending on the distance between the donor and the acceptor, different photochemical reactivity was observed. The shortest member of the dyad series acts as a photoacid while the longer donor-bridge-acceptor compounds exhibit proton-coupled electron transfer (PCET) chemistry. Our results provide insight into the importance of strong electronic communication between donor and acceptor units for observing PCET.

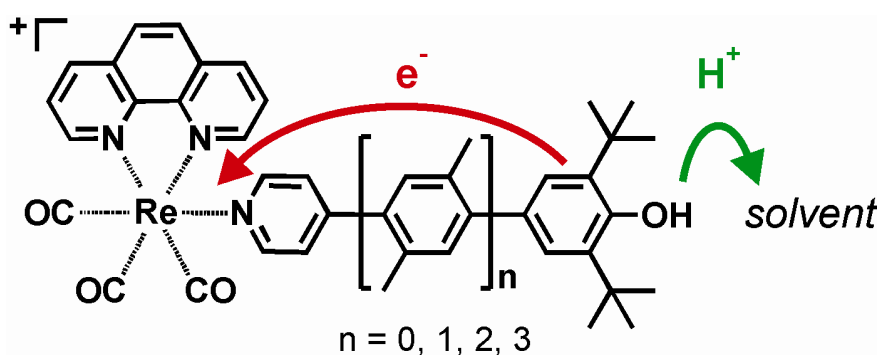

